\title{
The TIR-NBS-LRR protein CSA1 is required for autoimmune cell death in Arabidopsis pattern recognition co-receptor bak1 and bir3 mutants
}

Sarina Schulze ${ }^{1^{*}}$, Liping $\mathrm{Yu}^{1 *}$, Alexandra Ehinger ${ }^{1}$, Dagmar Kolb ${ }^{1}$, Svenja C. Saile ${ }^{1}$, Mark Stahl ${ }^{1}$, Mirita Franz-Wachtel ${ }^{2}$, Lei Li ${ }^{3}$, Farid El Kasmi ${ }^{1}$, Volkan Cevik ${ }^{4}$, Birgit Kemmerling ${ }^{1}$ \#

Affiliations

${ }^{1}$ ZMBP University of Tübingen, Auf der Morgenstelle 32, 72076 Tübingen, Germany

${ }^{2}$ Interfaculty Institute for Cell Biology, Department of Quantitative Proteomics, University of Tübingen, Auf der Morgenstelle 15, 72076 Tübingen, Germany

${ }^{3}$ Department of Molecular Biology, Max Planck Institute for Developmental Biology, 72076 Tübingen, Germany

${ }^{4}$ The Milner Centre for Evolution, Department of Biology and Biochemistry, University of Bath, Bath BA2 7AY, United Kingdom

${ }^{*}$ These authors contributed equally to this work

\#Corresponding author: Birgit Kemmerling, Auf der Morgenstelle 32, 72076 Tübingen, Germany

birgit.kemmerling@zmbp.uni-tuebingen.de

Key words: BAK1, cell death, BIR3, CSA1, PTI, ETI, PTI-ETI crosstalk, NLR, receptor kinase, guard

Short title: The NLR protein CSA1 mediates bak1 bir3 cell death 


\section{Abstract}

The BRI1-associated kinase BAK1/SERK3 is a positive regulator of multiple leucine rich receptor kinase-mediated signaling pathways including pattern triggered immunity (PTI). Absence or overexpression of BAK1 leads to spontaneous cell death formation. BAK1interacting receptors (BIR) constitutively interact with BAK1, and plants lacking or overexpressing BIR proteins phenocopy the cell death symptoms observed in bak1 knock outs or overexpressors. In the interactome of BIR3, the TIR-NBS-LRR protein CONSTITUTIVE SHADE-AVOIDANCE 1 (CSA1) was identified by mass spectrometry. CSA1 physically interacts with BIR proteins and can be detected in complexes with BAK1. Direct interaction was shown only for CSA1 with BIR proteins but not BAK1. Double mutant bak1 bir3 genotypes develop strong dwarfism and cell death symptoms that are dependent on EDS1 and salicylic acid. Loss of CSA1 blocks bak1 and bak1 bir3-mediated cell death formation thus demonstrating that CSA1 is causal for this type of cell death. We propose that CSA1 guards BIR proteins and initiates autoimmune cell death that is observed when BAK1 BIR complexes are impaired. Our findings reveal how cell death in the absence of BAK1 and BIR3 is executed and links BAK1, a common co-receptor of many pattern recognition receptors, to NLR proteins typically implicated in effector-triggered immunity. 


\section{Introduction}

Plants can recognize numerous signals to sense environmental threads and defend themselves against pathogens by perceiving extracellular and intracellular components of pathogens or microbes called microbe-associated molecular patterns (MAMPs) or effectors (Saur et al., 2020; Escocard de Azevedo Manhaes et al., 2021). Extracellular patterns are perceived by cell surface receptors belonging to the receptor kinase (RK) or receptor protein (RP) family (Wan et al., 2019). Effectors that are translocated into the plant cell are perceived by intracellular NOD-like receptors called nucleotide-binding leucine-rich repeat receptors (NLRs). NLRs sense effectors either directly or indirectly by guarding effector targets or effector decoys, mostly proteins important for or involved in immunity (Dangl and Jones, 2001). Both, MAMP and effector recognition leads to defense responses including reactive oxygen species production, salicylate accumulation and transcriptome changes that can fend off pathogens (Lu and Tsuda, 2021). NLRs are divided into the TOLL/INTERLEUKIN RECEPTOR (TIR)-NLRs (TNLs) and coiled-coil domain containing NLRs (CNLs). Downstream components are scarce but TNLs signal via the lipase-like protein ENHANCED DISEASE SUSCEPTIBILITY 1 (EDS1) that functions mutually exclusively either with PHYTOALEXIN DEFICIENT 4 (PAD4) or SENESCENCE ASSOCIATED GENE 101 (SAG101) (Lapin et al., 2020). By contrast, many CNLs signal via the integrin-like protein NON RACE SPECIFIC DISEASE RESISTANCE 1 (NDR1) (Aarts et al., 1998; Knepper et al., 2011). Many effector-sensing NLRs (sensor NLRs) require an additional subclade of NLRs, the RPW8-like helper NLRs that consist of the ACTIVATED DISEASE RESISTANCE 1 (ADR1) and N REQUIREMENT GENES 1 (NRG1) protein families (Jubic et al., 2019). ADR1 proteins can associate with EDS1 and PAD4 while NRG1 proteins only interact with EDS1/SAG101 complexes (Sun et al., 2020).

Leucine-rich repeat receptor kinases (LRR-RK) are the largest subfamily of cell surface receptors and have been assigned functions in many aspects of plant growth, development, and interaction with the environment (Gou et al., 2010). The BRASSINOSTEROID 
INSENSITIVE 1 (BRI1)-ASSOCIATED KINASE 1 (BAK1) belongs to a five-member LRR-RK subfamily with five LRRs, called SOMATIC EMBRYOGENESIS RECEPTOR KINASES 1 to 5 (SERK1-5) (Hecht et al., 2001). BAK1/SERK3 is a general regulator of other LRR-RKs (Chinchilla et al., 2009) by acting as an interactor and positive regulator of ligand-binding receptors (Chinchilla et al., 2007; Heese et al., 2007; Roux et al., 2011; Ladwig et al., 2015). The best-studied BAK1 interaction partners are FLAGELLIN SENSING 2 (FLS2), which senses bacterial flagellin (or the derived epitope flg22), and BRI1, the major Arabidopsis brassinosteroid $(\mathrm{BR})$ receptor. Biochemical and genetic analyses revealed that BAK1 functions as a co-receptor in both, BRI1 and FLS2 signaling pathways (Li et al., 2002; Nam and Li, 2002; Chinchilla et al., 2007; Heese et al., 2007). Meanwhile, many more RKs and also RPs (via SUPRRESSOR OF BIR1 (SOBIR1)) are linked to the BAK1 co-receptor (Liebrand et al., 2014). The crystal structures of the ligand-bound trimolecular receptor complexes have shown how SERK co-receptors bind to ligand-binding LRR-RKs as well as to the receptor-bound ligands (Santiago et al., 2013; Sun et al., 2013a; Sun et al., 2013b). Ligand-induced association with co-receptors is essential for transmembrane activation of RKs (Song et al., 2016; Hohmann et al., 2017). Subsequent transphosphorylation steps lead to full activation of the cytoplasmic kinase domains and initiation of signaling (Wang et al., 2008; Cao et al., 2013; Bojar et al., 2014).

Reduced levels or overexpression of BAK1 leads to deregulated cell death, indicating that a balanced receptor/co-receptor ratio needs to be maintained to prevent autoimmune cell death (He et al., 2007; Kemmerling et al., 2007; Dominguez-Ferreras et al., 2015). Double mutants of bak1 and its closest homolog BAK1-LIKE 1 (BKK1)/SERK4 strongly enhance the cell death phenotype of bak1 single mutants, leading to seedling lethality in double mutant nulls (He et al., 2007). BAK1 also interacts with all members of a family of small LRR-RK called BAK1-INTERACTING RECEPTOR-LIKE KINASES (BIR) which also have effects on cell death control (Gao et al., 2009; Halter et al., 2014; Imkampe et al., 2017; Ma et al., 2017; Hohmann et al., 2018). Four proteins BIR1 to BIR4 form the BIR protein family also named LRR-RK subgroup Xa (Shiu and Bleecker, 2001). Loss-of-function mutants in BIRs have a 
similar effect on cell death control as described for bak1 mutants. Furthermore, BIRs are negative regulators of BAK1-mediated immunity. BIRs act by constitutively interacting with BAK1 in the absence of ligands and thus prevent unwanted interaction with ligand-binding receptors. After ligand activation, BIRs are released from the complex and BAK1 can associate with the ligand-bound receptor complex partners. BIR2 affects flg22- and elf18induced signaling, as well as cell death control, but not BR signaling, while BIR3 has additionally an effect on BL signaling (Halter et al., 2014; Imkampe et al., 2017).

Modelling of the receptor complex revealed that a tripartite complex with BAK1, BRI1 and BIR3 is unlikely as BIR3 and BRI1 have a strong preference for the same binding site on BAK1 (Grosseholz et al., 2020). This is supported by the crystal structure of the extracellular domains of the BIR1 BAK1 complex that revealed an interaction interface that is very similar to the one that FLS2 uses for binding to BAK1 and therefore supports a competition of ligand binding receptors and BIR proteins for BAK1 (Ma et al., 2017; Hohmann et al., 2018).

Double mutant bak1 bir3 plants show a severe dwarf phenotype that is associated with spontaneous cell death, mimicking the phenotype of bak1 bkk1 mutants described above (Imkampe et al., 2017). Information on how bak1 and bir-mediated cell death is initiated and which pathway components are involved is still limited. A number of suppressor screens have been performed and only a few suppressors of bak1 bkk1 or bir1-mediated cell death have been published so far. These include glycosylation factors, ER quality control components, and nuclear import and export proteins (de Oliveira et al., 2016; Du et al., 2016). The bir1-mediated cell death is suppressed by sobir1, bak1 and pad4 mutation (Gao et al., 2009; Liu et al., 2016). Controversial outcomes have been reported for the rescue of bak1 bkk1-mediated cell death by pad4 or ndr1 mutation (de Oliveira et al., 2016; Gao et al., 2017). The bak1 bkk1 mutants cell death is rescued also by loss-of-function mutants of the cyclic nucleotide gated ion channel 20 (CNGC20) (Yu et al., 2019) and the nucleoporin suppressor of bak1 bkk1 (SBB1) mutant, a protein that controls nucleocytoplasmic trafficking (Du et al., 2016). MODIFIER OF SNC1 3 (MOS3) is a member of the same nuclear envelope complex and was identified as a nucleoporin that affects multiple disease resistance 
pathways. MOS3 mutation also suppresses bak1 bkk1-mediated cell death (Zhang and Li, 2005).. Recently Wu et al. (2020) revealed the helper NLR ADR1 family as part of the bak1 bkk1 cell death pathway. These data indicate that NLR signaling is involved in bak1- and maybe also bir-mediated cell death. But none of the screens have identified the guard or the specific signal that is needed for the cell death phenotypes.

Further evidence for a specific involvement of NLR-type resistance proteins in bak1 bir3mediated cell death comes from the mass spectrometry based interactome search of BIR3 where we identified the TNL CONSTITUTIVE SHADE AVOIDANCE 1 (CSA1) as a potential interactor of BIR3 (Faigon-Soverna et al., 2006). Our data show that BIR3 can interact with CSA1 and that bak1 and bak1 bir3-mediated cell death is blocked by mutation in csa1. This suggests that lack of wildtype (wt) BAK1 and/or BIR proteins activate CSA1 leading to cell death, indicating that functional integrity of the BAK1 BIR protein complex is guarded by CSA1.

\section{Results}

\section{Cell death in bak1 bir3 double mutant is dependent on EDS1, SA and NRGs}

To investigate how the absence of BAK1 and BIR3 initiates cell death we checked the potential immunity-related cell death pathways known in plants and created triple and quadruple mutants with components of these pathways. We crossed plants expressing a salicylic acid degrading bacterial enzyme NahG and mutants of known ETI pathway components such as eds1, pad4 and sag101 with bak1 bir3 mutants. The eds1 mutant can partially block bak1 bir3-mediated growth phenotypes (Figure 1A), and after Alternaria brassicicola infection cell death is reduced to wt levels and infection symptoms are as low as in the hyperresistant eds1 mutant (Figure 1B-D). The effect of eds1 mutation on the bak1 bir3 phenotype suggests that a TNL might be involved in guarding the BAK1 BIR3 complex and initiate cell death when one or both of the components are absent. pad4 and sag101 mutants had only a weak effect on the bak1 bir3 growth phenotype (Supplemental Figure1). This indicates that the EDS1 SAG101 or EDS1 PAD4 hubs in NLR-mediated immunity 
downstream of TNLs are redundantly and at least partially necessary for bak1 bir3-mediated cell death. SA is indispensable for bak1-mediated cell death (Gao et al., 2017). Expression of NahG, that degrades salicylic acid, also affects bak1 bir3-mediated cell death (Supplemental Figure1). Our findings show that wt BAK1 and BIR3 contain cell death that is executed by EDS1-dependent complexes and SA, leading to autoimmunity-associated runaway cell death in plants lacking a functional BAK1 BIR3 complex. This suggests that components of the TNL-mediated ETI pathway contribute to and are necessary for bak1 bir3-mediated cell death, but the requirement of additional components for the observed phenotypes also needs to be postulated.

Lapin et al. (2019) postulated that EDS1-SAG101 and NRG1s co-evolved as a functional TNL-dependent cell-death and resistance module. Since we observed a partial suppression of the bak1 bir3 phenotype by eds 1 , we determined whether the NRG1 family is also involved in mediating bak1 bir3 cell death. Therefore, we crossed nrg1.1 nrg1.2 double mutants with bak1 bir3 double mutants. The nrg1.1 nrg1.2 bak1 bir3 mutants are larger than bak1 bir3 mutants showing that NRG1s, as part of the TNL cell death pathway, are also contributing to the bak1 bir3 phenotype (Supplemental Figure 2).

\section{The interactome of BIR3 contains the TNL CSA1}

We determined the in vivo interactome of BIR3-YFP by liquid chromatography-electron spray ionization tandem mass spectrometry (LC-ESI-MS/MS) in Arabidopsis plants. MS analyses revealed BAK1 and other SERKs as the most abundant interaction partners of BIR3 (Supplemental Table 1), confirming the strong interaction with BAK1 published previously (Xing et al., 2007; Gao et al., 2009; Halter et al., 2014; Imkampe et al., 2017). In addition, other known RKs such as SOBIR1, FERONIA and MIK2 have been detected, indicating that BIR3 interacts with multiple known but also yet undescribed RKs (Liebrand et al., 2014; Stegmann et al., 2017; Van der Does et al., 2017). Thus, BIR3 seems to be a general interactor of RKs and therefore likely also affects multiple signaling pathways (Supplemental Table 1). 
From the BIR3-interacting protein candidates we identified a protein with a unique peptide sequence LPDSLGQLK of a known NLR as a potential candidate for executing cell death in bak1 bir3 genotypes. (Supplemental Figure 3A). This peptide corresponds to the TNL protein CONSTITUTIVE SHADE AVOIDANCE 1 (CSA1) that was previously shown to affect shade avoidance (Faigon-Soverna et al., 2006) and autoimmunity (Xu et al., 2015) (Supplemental Figure $3 \mathrm{~B}, \mathrm{C})$.

CSA1 is indispensable for the autoimmune phenotypes initiated by hyperactive CHILLING SENSITIVE 3 (CHS3) alleles, an NLR-encoding gene localized adjacent to CSA1 on chromosome 5. CSA1 and CHS3 are proposed to act together as a sensor and executer pair of NLRs (Xu et al., 2015; Castel et al., 2019; Wu et al., 2019). The identification of CSA1 in our BIR3-interactome and the partial suppression of the bak1 bir3 phenotype by components of TNL-mediated immunity strongly suggest a potential involvement of CSA1 in the bak1 bir3 cell death phenotype.

\section{BIR3 interacts with CSA1}

To confirm the interaction of CSA1 and BIR3 identified in planta by MS analysis, coimmunoprecipitation (co-IP) experiments were performed. BIR3-GFP and CSA1-V5 fusion proteins were expressed under the constitutively active $35 \mathrm{~S}$ promoter in Nicotiana $(N$.) benthamiana. For the expression of respective proteins, p19, a silencing suppressor, was coinfiltrated in order to suppress the RNA silencing machinery of the plant. Leaves infiltrated with p19 only served as negative controls to detect unspecific binding of proteins to the beads used for immunoprecipitation. Expression of CSA1-V5 and BIR3-GFP alone served as additional negative controls, to ensure that no unspecific binding to the beads is detected instead of proteins co-immunoprecipitated with BIR3-GFP. CSA1 is detectable in the coimmunoprecipitated samples but not in control samples, suggesting that CSA1 can interact with BIR3 (Figure 2). Interaction studies in Arabidopsis turned out to be limited due to technical and biological difficulties. Expression of genomic constructs of CSA1-V5 result in low expressing or lethal plants, the BIR3 antibody has a low affinity and is insufficient to 
detect co-immunoprecipitated BIR3 and the amount of expressed and detectable immunoprecipitated CSA1 was too little to prove interaction. The other expressed BIR family members BIR1 and 2 can also interact with CSA1 in co-IP after transient expression in $N$. benthamiana (Supplemental Figure 4).

Localization studies with fractionated plant extracts and confocal laser scanning microscopy revealed that CSA1 is predominantly localized to microsomal fraction and the plasma membrane, respectively (Supplemental Figure 5), which is in agreement with interaction of plasma membrane-resident BIR3.

To support these data, BIR3 and CSA1 coding sequences fused to the $\mathrm{N}$ - and C-terminal parts of Luciferase (Luc) were transiently expressed in planta ( $N$. benthamiana) and tested for restoration of luciferase enzyme activity. The increase in luciferase activity, as quantified by relative light units emitted from degraded luciferin, shows that the luciferase can reconstitute when CSA1-NLuc and BIR3-CLuc are expressed together but not when expressed with the empty vector controls, confirming that also in this experimental setup CSA1 and BIR3 are interacting in planta (Figure 2 B; Supplemental Figure 6).

\section{The interaction of CSA1 and BIR3 is direct}

While proteins detected in co-IPs do not necessarily interact directly, the Split-LUC assays already suggests a very close vicinity of the proteins. If this is indeed a direct interaction was tested with the Split-ubiquitin assay (SUS) in yeast. CSA1 and BIR3 were fused to N- and Cterminal parts of ubiquitin and expressed in yeast. The growth rescue on limiting medium strongly suggests that CSA1 can directly interact with BIR3 but not with BAK1 (Figure 2 C; Supplemental Figure 7). We hypothesize that CSA1 directly guards BIR3 and that cell death in bak1 mutants may be mediated via BIR3 by CSA1.

\section{The CSA1 partner CHS3 does not interact directly with BIR3}

CSA1 works as a pair with its genetic neighbor the TNL protein CHILLING SENSITIVE 3 (CHS3) (Xu et al., 2015; Van de Weyer et al., 2019). In a suppressor screen for auto-active 
chs3-2D mutants CSA1 was found to be indispensable for the execution of the autoimmune cell death exhibited by the auto-active chs3-2D allele (Xu et al., 2015). CHS3 is a TNL with

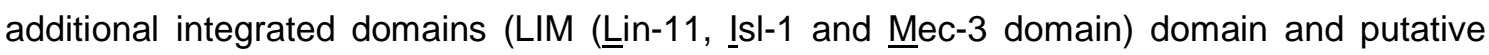
DA-1 protease domain) at the C-terminus (Yang et al., 2010) and encoded in a head-to-head orientation with CSA1 (Supplemental Figure 8). Furthermore, CSA1 and CHS3 were found to specifically associate in Arabidopsis as well as in N. benthamiana plants (Parkes, 2020). We detected CHS3 in co-IPs with BIR3 when both proteins were transiently expressed in $N$. benthamiana (Figure $3 \mathrm{~A}$ ). BIR1 and BIR2 can also interact in co-IPs with $\mathrm{CHS} 3$ (Supplemental Figure 9). In all assays the interaction appeared weaker than the CSA1 BIR3 interaction. The BIR3 CHS3 interaction was neither confirmed in Split-Luc assays nor in SUS assays indicating that CSA1 is the direct interactor and that CHS3 might be part of the same complex but not in physical contact with BIR3 (Figure3 B, C; Supplemental Figure 6, 7).

\section{CSA1 and CHS3 are in complex with BAK1}

If CSA1 and CHS3 are in complexes with BIR3 the question arises if they also interact with BAK1. BAK1-GFP and CSA1 can be detected in the same co-immunoprecipitated complexes, when transiently expressed in $N$. benthamiana (Figure $4 \mathrm{~A}$ ). However, we failed to confirm this interaction in Split-luciferase and SUS assays (Fig 4 B, C). These results indicate that BAK1 and CSA1 might be part of the same complex, but they most likely do not physically interact. Weak interaction of CHS3 with BAK1 was also detectable in co-IPs of transiently expressed tagged proteins, but neither in Split-Luc assays nor in SUS assays a close vicinity or direct interaction could be shown (Figure 5), similar to the BAK1 CSA1 association. Subcellular localization assays show that CHS3 is localized to the plasma membrane but also to the soluble fraction and can be localized in the nucleus, which is in agreement with a weaker interaction with membrane-resident RKs (Supplemental Figure 5).

Taken together, these data indicate that CSA1 guards BIR proteins by directly interacting with them and CHS3 and BAK1 are partners in CSA1 complexes but not direct interaction 
partners in this complex. Whether BAK1 and CHS3 are simultaneously in complex with CSA1 needs to be studied in future experiments.

\section{CSA1 is required for bak1 bir3-mediated cell death}

Loss of BAK1 and BIR3 causes strong autoimmune cell death in Arabidopsis (Imkampe et al., 2017). As we identified CSA1 in the interactome of BIR3, we generated a bak1 bir3 csa1 triple mutant to test whether loss of CSA1 can block bak1 bir3-initiated cell death. The triple mutants are significantly larger, fertile and less affected in autoimmune cell death (Figure 6 A). The cell death and spreading necrosis observed in bak1 and bak1 bir3 mutants upon Alternaria (A.) brassicicola infections is inhibited in bak1 bir3 csa1 triple mutants (Figure 6 C,D). SA levels that are strongly enhanced in bak1 bir3 double mutants are reverted in the bak1 bir3 csa1 triple mutant to levels detectable in the single mutant parents (Figure $6 \mathrm{E}$ ). PAMP-induced ROS burst is not affected in csa1 mutants while basal and PAMP- induced FRK1 gene expression that is strongly induced in bak1 bir3 double mutants is lowered to single bak1 mutant levels in the bak1 bir3 csa1 triple mutant (Figure $6 \mathrm{~F}, \mathrm{G}$ ) indicating that CSA1-mediated cell death responses potentiate flg22-triggered immune responses. The bir1 dwarfism phenotype is not affected by csa1 mutation indicating that bir1 and bak1 bir3 cell death are not identical and require different downstream components (Supplemental Figure 10).

Crosses of bak1 bir3 with chs3 mutants revealed that CHS3 is less involved in the growth phenotype as is CSA1 (Supplemental Figure $11 \mathrm{~A}$ ). However, loss of CHS3 in the bak1 bir3 background also affects the autoimmune cell death shown by trypan blue staining of uninfected plants and the cell death induced by Alternaria infections (Supplemental Figure 11 $B, C)$. This suggests that CHS3 is partially contributes to the autoimmune cell death symptoms and the development of spreading cell death after Alternaria infections in the bak1 bir3 mutant (Supplemental Figure 11 C, D).

Altogether, these data show that CSA1 and, to a lesser extent, also CHS3 are necessary for triggering autoimmune cell death in bak1 bir3 mutants. The TNL CSA1 interacts with BIR3 
and induces cell death reactions in the absence of BAK1 and/or BIR3 and thus acts as a guard of functional, active BIR3.

\section{CSA1 is required for bak1-mediated cell death}

If CSA1 can only interact with BIR3 directly and not with BAK1 does it also guard BAK1 and mediates bak1 loss of function cell death? We crossed csa1 also to bak1 alone and monitored the macroscopic phenotype and cell death. Macroscopically bak1 csa1 mutants are similar to bak1 single mutants (Figure 7A). As the bak1 mutants show only weak spontaneous cell death without any trigger, we infected the indicated genotypes with $A$. brassicicola and scored the disease index. In the double mutant bak1 csa1, both, disease indices and visible symptoms are significantly weaker as compared to those in bak1 single mutants and resemble the phenotype of csa1 mutants that are slightly less affected than the Col-0 wt plants (Figure 7 B-E). PAMP responses, for example ROS burst after flg22 treatment and FRK1 gene expression, of the bak1 csa1 mutants are identical to those observed in bak1 single mutant responses, suggesting that CSA1 is necessary for the cell death responses triggered in bak1 mutants but not for the PAMP responses (Figure $7 \mathrm{~F}, \mathrm{G}$ ). Complementation of the bak1 csa 1 mutants and the bak1 bir3 csa1 mutants with a genomic construct expressing CSA1 under its own promoter complement mutant phenotypes and restore strong cell death symptoms typically observed in bak1 and bak1 bir3 mutants (Supplemental Figure 12, 13).

This demonstrates that CSA1 mediates bak1-mediated cell death responses and provides evidence for a model with BIR3 being a direct interactor of CSA1 and BAK1, in which CSA1 monitors ("guards") functional integrity of the BAK1 BIR protein complex that is required for preventing autoimmune cell death in wt plants.

\section{Discussion}

Cell death in bak1 mutants is a phenomenon that was reported first in 2007 (He et al., 2007; Heese et al., 2007; Kemmerling et al., 2007). Loss-of-function mutants in BAK1-interacting 
receptors BIR1, BIR2 and BIR3 phenocopy these autoimmune cell death phenotypes (Gao et al., 2009; Halter et al., 2014; Imkampe et al., 2017). Since then, multiple components that are necessary for the execution of the bak1-mediated cell death have been revealed. In suppressor screens, often the double mutant bak1-3 bkk1 and bak1-4 bkk1 were used as the loss of the two closely related SERK family members results in a strong autoimmune cell death phenotype associated with severe dwarfism or even seedlings lethality ( $\mathrm{He}$ et al., 2007; Albrecht et al., 2008; Schwessinger et al., 2011; de Oliveira et al., 2016; Du et al., 2016; Gao et al., 2017; Wu et al., 2020). The following components have been shown to suppress BAK1 or BIR cell death: ER quality control components such as ENDOPLASMIC RETICULUM DNAJ DOMAIN-CONTAINING PROTEIN 3B (ERdj3b) and STROMAL CELLDERIVED FACTOR 2 (SDF2) (Sun et al., 2014), the protein glycosylation machinery component STAUROSPORIN AND TEMPERATURE SENSITIVE3 (STT3a) protein (de Oliveira et al., 2016), the cyclic nucleotide gated ion channel 20 (CNGC20) (Yu et al., 2019), the nucleocytoplasmic trafficking component SUPPRESSOR OF BAK1 BKK1/ NUCLEOPORIN 85 (SBB1/NUP85) and the DEAD-box RNA helicase 1 (DRH1) (Du et al., 2016) and the helper NLR family ADR1 (Wu et al., 2020). A direct detection system or downstream component that senses the absence of BAK1 or BIR proteins was not found.

Effects of bir1 mutations are partially suppressed by mutations in classical ETI components such as eds 1 and pad4 mutations and bak1 cell death is affected by salicylic acid induction deficient 2 (sid2), eds5 mutations, indicating that bak1- and bir1-mediated cell death is conveyed by SA and potentially involve TNL proteins (Gao et al., 2009; Gao et al., 2017). We also tested multiple ETI downstream components and found that eds1 (pad4 and sag101) are partially required for bak1 bir3 phenotypes, suggesting that TNLs could also be important for this type of cell death. Crosses with the NRG1 family mutants revealed a contribution of NRG1 helper NLRs in bak1 bir3-mediated phenotypes. Despite the fact that bak1 bkk1 cell death is fully dependent on the other helper-NLR family of ADR1 proteins, this shows that bak1 bir3 mediates cell death is distinct from the bak1 bkk1 cell death and requires the NRG1s that are linked to TNLs and especially to the CSA1 CHS3 pair of NLRs (Wu et al. 
2020; Saile et al, 2020; Wu 2019). If the ADR1 family is additionally involved in bak1 bir3 cell death needs to be tested in the future. As none of the previously performed genetic screens revealed the direct guard of BAK1 or BIR3, we performed IP-MS analyses with BIR3-YFP and identified the TNL CSA1 as a direct interactor of BIR3 but not BAK1. This explains also why previous interaction studies with BAK1 have not revealed this guard as CSA1 does not directly interact with BAK1 but with its "bodyguard" protein BIR3 and also other BIR proteins.

The IP-MS interactome of BIR3 revealed about $30 \mathrm{RKs}$ as candidate interactors. This broadens the spectrum of RKs that can be assessed by BIR3 and will allow the functional determination of more orphan RKs (Hohmann et al., 2018; Hohmann et al., 2020). RKs associated with BIR proteins are potentially also guarded by NLRs. This might explain how other RKs confer autoimmune cell death such as e.g. SOBIR1 (Gao et al., 2009; Liebrand et al., 2014).

CSA1 and CHS3 are working as a pair in controlling autoimmune cell death (Xu et al., 2015; Castel et al., 2019; Wu et al., 2019). CSA1 can directly interact with BIR3 but not with BAK1, while CHS3 could not be shown to directly interact with BIR3 or BAK1. This suggests a complex with BAK1 interacting strongly with BIR3, BIR3 interacting with CSA1 and CSA1 interacting with CHS3 (Parkes, 2020). The indirect interaction assayed by co-IPs reveals the complex composition also for more distantly associated components. As CSA1 is also necessary for cell death initiated in bak1 single mutants we propose a model in which CSA1 guards BIR3 directly and the BAK1 BIR3 complex integrity. The activation mechanism of the NLR CSA1 by the absence of BIR3 and/or BAK1 is still elusive, but conformational changes by losing the interaction interface with the receptor complex or transphosphorylation leading to de-repression of the NLR, similar to what is described for RRS1 release and reorganization of the RPS4 complex, appear possible (Williams et al., 2014; Lolle et al., 2020).

Lack of CSA1 can strongly suppress the bak1 bir3 cell death phenotype, showing that CSA1 is necessary for this cell death execution. Mutations in CHS3 are less effective and therefore 
bak1 bir3-mediated cell death is different from the chs3-2D autoimmune phenotype that is fully dependent on CSA1 (Xu et al., 2015).This is in line with the fact that CSA1 can directly interact with BIR3, but CHS3 does not, and supports the model that CSA1 guards BIR3 directly, potentially bypassing the sensor NLR CHS3 that is only marginally involved in the bir3 bak1-mediated cell death.

The phenotype of the triple bir3 bak1 csa1 mutant does not fully rescue the cell death phenotype exerted by bak1 bir3 mutations. Other components of the pathway as SA or EDS1 have even less effects. Redundancy within the NLR family might be the reason for this as RPS4 for example is able to complement the reported csa1 phenotypes (Faigon-Soverna et al., 2006). Also, differential requirement for the two groups of helper NLRs, ADR1s and NRG1s can explain these phenotypes, as BAK1 might preferentially contain cell death via ADR1 suppression, while BIR3 via CSA1 might suppress cytoplasmic cell death activation via the NRG1 family (Wu et al., 2019; Wu et al., 2020).

Though CSA1 is reported to be necessary for chs3-2D activated autoimmune cell death, no effector has been identified yet that targets CSA1 or CHS3. BAK1 is targeted by multiple effectors as reported previously for e.g. AvrPto, AvrPtoB, HopF2 and HopB1 (Shan et al., 2008; Zhou et al., 2014; Li et al., 2016). The CSA1 guard has potentially evolved to surveil BAK1 BIR complex integrity to prevent downregulation of PTI by effectors disturbing BAK1 function. Another option is that BAK1-BIR3 complexes are sensed by CSA1 to avoid incompatibility or prevent loss of this central and multifunctional co-receptor complex. A similar scenario was reported for STRUBBELIG RECEPTOR FAMILY 3 (SRF3), an LRRRLK structurally similar to BIR proteins (Imkampe et al., 2017), that confers hybrid incompatibility along with the R protein RPP1, with SRF3 being guarded by RPP1 to control incompatibility in the absence of pathogens (Alcazar et al., 2010).

BAK1 as a classical PTI co-receptor is linked to an NLR that is classically part of the ETI pathway. Recent work suggests that PTI is required for proper ETI and HR cell death, but the mechanism of this interplay is still elusive (Ngou et al., 2021; Yuan et al., 2021). Mutants in 
CSA1 are slightly more susceptible to bacterial pathogens (Faigon-Soverna et al., 2006).

CSA1 can interact with components from both extracellular and intracellular immune receptors and may provide a link between both immune systems. Early PTI responses are not altered in csa1 mutants (Figure 6, 7) but bacterial resistance to Pto DC3000 avrRpt2 is impaired, indicating that plant resistance is affected by loss of CSA1 (Faigon-Soverna et al., 2006). This points to an effective interaction of the NLR protein CSA1 with pattern recognition receptor complexes, and lack of interaction result in HR cell death, potentially enhancing plant resistance to biotrophic pathogens (Faigon-Soverna et al., 2006). Depletion of BAK1 after infection might be used by fungal pathogens to improve virulence by cell death induction in the plant (Yamada et al., 2016).

\section{Conclusion}

Here we describe the TNL protein CSA1 to interact physically and genetically with BIR3 and thereby senses BIR3/BAK1-complex integrity and induces cell death when the complex integrity is disturbed. The identification of CSA1 helps explaining the cell death phenotypes of bak1 and bir3 mutants as a result of a surveillance system that controls the integrity of this essential PTI co-receptor complex by an NLR protein typically involved in ETI signaling. To find out if this involves microbial effectors that target the PTI co-receptors or if activation of BAK1 results in additional activation of ETI-responses that amplify PTI responses or if it is a result of linking NLR-mediated autoimmune cell death with PTI responses will be an interesting challenge for the future.

\section{Materials and Methods}

\section{Plant material and growth conditions}

Plants were grown for 5 to 6 weeks on soil in growth chambers under short day conditions (8 $\mathrm{hr}$ light, $16 \mathrm{hr}$ dark; $22^{\circ} \mathrm{C} ; 110 \mu \mathrm{Em}^{-2} \mathrm{~s}^{-1}$ ), for five to six weeks under long day conditions (16hr light, $8 \mathrm{hr}$ dark) or on $1 / 2 \mathrm{MS}$ medium.

Mutants used are bir3-2 (Salk_116632), bak1-4 (SALK_116202), csa1-2 (SALK_023219) 
chs3-3 (SALK_063886), eds1-12 (Ordon et al., 2017), pad 4-1 (Glazebrook et al., 1996), sag101-2 (Feys et al., 2005), nrg1.1, nrg1.2. (Castel et al., 2019). Lines were crossed with bak1-4 and bak1-4 bir3-2. NahG expressing lines were crossed with bak1-4 and bak1-4 bir32 lines. All lines were genotyped with the primers indicated in STable2.

Constructs for stable transformed Arabidopsis and for transient expression in $N$. benthamiana pBIR3-BIR3-eGFP, pBAK1-BAK1-eGFP, 35S-BIR2-YFP, 35S-BIR1-eGFP were described previously (Halter et al., 2014; Imkampe et al., 2017). To clone the genomic fragment containing CSA1 (At5g178880), TAC clone JAtY79I19 obtained from Arabidopsis accession Col-0 was digested with Kpnl (NEB) and Sall (NEB), and a 7,959 bp fragment harbouring proCSA1:gCSA1 was purified from agarose gel and cloned into Kpnl and Sall digested pCambia2300.

Cloning of 35S-CSA1-V5 and 35S-CHS3-V5 was carried out using Uracil-Specific Excision Reagent (USER) method (Nour-Eldin et al., 2010). CSA1 and CHS3 were amplified from TAC clone JAtY79I19 with the primers USER-CSA1-F/USER-CSA1-R and USER-CHS3F/USER-CHS3-R, respectively. The resulting PCR products together with V5-tag amplicons (amplified with USER-V5-F/USER-V5-R) were cloned into LBJJ234 vector pre-linearized with Pacl and Nt.Bbvcl as described by (Redkar et al., 2021).

GFP-fusion proteins of CSA1 and CHS3 were generated by amplification from Col-0 cDNA with the primers listed in STable 2 and cloning into pENTR-TOPO (Thermofischer) and recombination into pB7FWG2 (Karimi et al., 2002).

Genomic clones for complementation were amplified from pCAMBIA2300 clones described above with the primers listed in STable2, cloned in pENTR-TOPO (Thermofischer) and recombined in pFAST-G01. The constructs were transformed in Agrobacterium strain GV3101 and transformed in bak1 csa1 and bak1 bir3 csa1 plants by floral dipping (Clough and Bent, 1998).

\section{Infection procedures}


Alternaria brassicicola infection assays were carried out as described by Kemmerling et al. (2007).

\section{Histochemical assays}

Cell death and fungal mycelium was detected with trypan blue staining as described in Kemmerling et al. (2007).

\section{Oxidative burst measurements}

Oxidative burst was measured with a luminol-based assay as described in Halter et al. (2014)

\section{RT-PCR analysis}

Transcript levels were analyzed by quantitative RT-PCR (qRT-PCR) as described by Mosher et al. (2013) with primers listed in Supplemental Table S2.

\section{Hormone measurements}

Salicylate contents were measured as described by Lenz et al. (2011).

\section{Transient expression in Nicotiana benthamiana}

BIR3, BAK1, BIR2, BIR1, CSA1 CHS3 constructs described above were transformed into Agrobacterium strain GV3101 or C58 and transiently expressed in $N$. benthamiana as described in Halter et al. (2014).

\section{Co-immunoprecipitations}

Leaves were ground in liquid nitrogen, and $250 \mu$ l extraction buffer $(50 \mathrm{mM}$ Tris- $\mathrm{HCl} \mathrm{pH} 8.0$, $150 \mathrm{mM} \mathrm{NaCl}, 1 \%$ Nonidet P40, proteinase inhibitor cocktail (Roche)) per $200 \mathrm{mg}$ tissue powder was added. Samples were homogenized and incubated for $1 \mathrm{~h}$ at $4^{\circ} \mathrm{C}$ under gentle shaking. Samples were centrifuged two times at $4^{\circ} \mathrm{C}$ and $14,000 \mathrm{rpm}$ for $10 \mathrm{~min}$ to obtain a clear protein extract. After washing with extraction buffer, either $15 \mu \mathrm{l}$ of GFP-trap or V5-trap beads (Sigma, Chromotec) were used. Supernatants containing equal amounts of protein were incubated for $1 \mathrm{~h}$ at $4^{\circ} \mathrm{C}$ with the beads. Beads were washed two times with $50 \mathrm{mM}$ 
Tris- $\mathrm{HCl} \mathrm{pH} 8.0,150 \mathrm{mM} \mathrm{NaCl}$ and one time with $50 \mathrm{mM}$ Tris- $\mathrm{HCl} \mathrm{pH} 8.0,50 \mathrm{mM} \mathrm{NaCl}$ before adding SDS sample buffer and heating at $95^{\circ} \mathrm{C}$ for $5 \min$.

\section{SDS-PAGE and immunoblotting}

Proteins were separated, blotted, and incubated with antibodies as described by Schulze et al. (2010) but using $8 \%$ SDS gels and the following antibody dilutions: anti-GFP (Abcam), 1:3,000; anti-HA (Sigma), 1:2,000; anti-V5 (Sigma), 1:2,000; anti-BAK1 (Agrisera), 1:3,000; anti-BIR3 antibodies were obtained from rabbits immunized with the peptide CVGSRDSNDSSFNN fused to KLH (Agrisera) 1:500; anti-luciferase (Sigma), 1:3,000; antiVP16 (Santa Cruz), 1:1000; anti-ATPase (Agrisera), 1:5,000; 1:5,000; anti-rabbit (Sigma),1:50,000; anti-goat (Sigma), 1:10,000; anti-mouse (Sigma), 1:10,000. Chemiluminescence was detected with the ECL Western blotting detection system (GE Healthcare) and a CCD camera (Amersham Imager 600). If figures were reconstituted from images of blots, lanes from the same blot are shown in one panel of a figure even if they were in a different order on the original blot (separated by dotted lines). Data from different blots are shown in separate figure parts.

\section{Mass spectrometry analyses}

Coomassie-stained gel pieces were digested in gel with trypsin as described previously (Borchert et al., 2010). After desalting using C18 Stage tips (Rappsilber et al., 2007), extracted peptides were separated on an EasyLC nano-HPLC coupled to a Q Exactive HF mass spectrometer (both Thermo Fisher Scientific) as described elsewhere (Kelstrup et al., 2014) with slight modifications: the peptide mixtures were injected onto the column in HPLC solvent $A(0.1 \%$ formic acid) at a flow rate of $500 \mathrm{nl} / \mathrm{min}$ and subsequently eluted with a 57 minute segmented gradient of $10-33-50-90 \%$ of HPLC solvent B $(80 \%$ acetonitrile in $0.1 \%$ formic acid) at a flow rate of $200 \mathrm{nl} / \mathrm{min}$. Full scan was acquired in the mass range from $\mathrm{m} / \mathrm{z}$ 300 to 1650 at a resolution of 120,000 followed by HCD fragmentation of the 7 most intense precursor ions. High-resolution HCD MS/MS spectra were acquired with a resolution of 
60,000. The target values for the MS scan and MS/MS fragmentation were $3 \times 10^{6}$ and $10^{5}$ charges, respectively. Precursor ions were excluded from sequencing for $30 \mathrm{~s}$ after MS/MS.

\section{Data processing}

Acquired MS spectra were processed with MaxQuant software package version 1.5.1.0 (Cox and Mann, 2008) with integrated Andromeda search engine (Cox et al., 2011). The database search was performed against a target-decoy Arabidopsis thaliana database obtained from Uniprot, containing 33,351 protein entries, and 245 commonly observed contaminants. Endoprotease trypsin was defined as protease with a maximum of two missed cleavages. Oxidation of methionine and $\mathrm{N}$-terminal acetylation were specified as variable modifications, whereas carbamidomethylation on cysteine was set as a fixed modification. Initial maximum allowed mass tolerance was set to $4.5 \mathrm{ppm}$ (for the survey scan) and $20 \mathrm{ppm}$ for HCD fragment ions. Peptide, protein and modification site identifications were reported at a false discovery rate (FDR) of 0.01 , estimated by the target/decoy approach (Elias and Gygi, 2007).

\section{Yeast split ubiquitin assay}

BAK1, BIR3, CSA1 and CHS3 cDNAs were amplified with the primers listed in STable 2 and cloned into pCR8 according to the manufacturers protocol and recombined into pXNubA22Dest and pMetYC-Dest vectors for direct interaction assays of membrane proteins in yeast using the split-ubiquitin system (SUS) (Grefen et al., 2009). Yeast assays were performed as described in Halter et al., (2014)

\section{Split-Luciferase assay}

BIR3 and BAK1 cDNA and CSA1 and CHS3 genomic coding sequences were amplified with the primers listed in STable 2 and classically cloned into the KpnI Sall restriction sites of the vectors pCAMBIA-NLuc and pCAMBIA-CLuc for expression in Nicotiana benthamiana. The Split-Luciferase assays were performed as described in Zhou et al. (2018).

\section{Statistical Methods}


Statistical significance between two samples was tested with Student's t-test, between

groups statistical significance was analyzed using one-way ANOVA combined with Tukey's honest significant difference (HSD) test. Significant differences are indicated with different letters $(p<0.05)$.

\section{Accession numbers}

BIR3: At1g27190; BIR2: At3g28450; BIR1: At3g48380; BAK1/SERK3: At4g33430; BKK1/SERK4: At2g13790; CSA1: AT5G17880; CHS3:At5g17890; EDS1:At3g48090; PAD4: At3g53420; SAG101: At5g14930, NRG1.1: At5g66900 NRG1.2: At5g69910.

\section{References}

Aarts, N., Metz, M., Holub, E., Staskawicz, B.J., Daniels, M.J., and Parker, J.E. (1998). Different requirements for EDS1 and NDR1 by disease resistance genes define at least two R genemediated signaling pathways in Arabidopsis. Proc Natl Acad Sci U S A 95, 10306-10311.

Albrecht, C., Russinova, E., Kemmerling, B., Kwaaitaal, M., and de Vries, S.C. (2008). Arabidopsis SOMATIC EMBRYOGENESIS RECEPTOR KINASE proteins serve brassinosteroid-dependent and -independent signaling pathways. Plant Physiol. 148, 611-619.

Alcazar, R., Garcia, A.V., Kronholm, I., de Meaux, J., Koornneef, M., Parker, J.E., and Reymond, M. (2010). Natural variation at Strubbelig Receptor Kinase 3 drives immune-triggered incompatibilities between Arabidopsis thaliana accessions. Nat. Genet. 42, 1135-1139.

Bojar, D., Martinez, J., Santiago, J., Rybin, V., Bayliss, R., and Hothorn, M. (2014). Crystal structures of the phosphorylated BRI1 kinase domain and implications for brassinosteroid signal initiation. Plant J. 78, 31-43.

Borchert, N., Dieterich, C., Krug, K., Schutz, W., Jung, S., Nordheim, A., Sommer, R.J., and Macek, B. (2010). Proteogenomics of Pristionchus pacificus reveals distinct proteome structure of nematode models. Genome Res 20, 837-846.

Cao, Y., Aceti, D.J., Sabat, G., Song, J., Makino, S., Fox, B.G., and Bent, A.F. (2013). Mutations in FLS2 Ser-938 dissect signaling activation in FLS2-mediated Arabidopsis immunity. PLOS Pathog 9, e1003313.

Castel, B., Ngou, P.M., Cevik, V., Redkar, A., Kim, D.S., Yang, Y., Ding, P., and Jones, J.D.G. (2019). Diverse NLR immune receptors activate defence via the RPW8-NLR NRG1. New Phytol 222, 966-980.

Chinchilla, D., Shan, L., He, P., de Vries, S., and Kemmerling, B. (2009). One for all: the receptorassociated kinase BAK1. Trends Plant Sci. 14, 535-541.

Chinchilla, D., Zipfel, C., Robatzek, S., Kemmerling, B., Nürnberger, T., Jones, J.D.G., Felix, G., and Boller, T. (2007). A flagellin-induced complex of the receptor FLS2 and BAK1 initiates plant defence. Nature 448, 497-500.

Clough, S.J., and Bent, A.F. (1998). Floral dip: a simplified method for Agrobacterium-mediated transformation of Arabidopsis thaliana. Plant J 16, 735-743.

Cox, J., Neuhauser, N., Michalski, A., Scheltema, R.A., Olsen, J.V., and Mann, M. (2011). Andromeda: a peptide search engine integrated into the MaxQuant environment. Journal of proteome research 10, 1794-1805.

Dangl, J.L., and Jones, J.D. (2001). Plant pathogens and integrated defence responses to infection. Nature 411, 826-833. 
de Oliveira, M.V., Xu, G., Li, B., de Souza Vespoli, L., Meng, X., Chen, X., Yu, X., de Souza, S.A., Intorne, A.C., de, A.M.A.M., Musinsky, A.L., Koiwa, H., de Souza Filho, G.A., Shan, L., and He, P. (2016). Specific control of Arabidopsis BAK1/SERK4-regulated cell death by protein glycosylation. Nature Plants 2, 15218.

Dominguez-Ferreras, A., Kiss-Papp, M., Jehle, A.K., Felix, G., and Chinchilla, D. (2015). An Overdose of the Arabidopsis Coreceptor BRASSINOSTEROID INSENSITIVE1-ASSOCIATED RECEPTOR KINASE1 or Its Ectodomain Causes Autoimmunity in a SUPPRESSOR OF BIR1-1-Dependent Manner. Plant Physiol. 168, 1106-1121.

Du, J., Gao, Y., Zhan, Y., Zhang, S., Wu, Y., Xiao, Y., Zou, B., He, K., Gou, X., Li, G., Lin, H., and Li, J. (2016). Nucleocytoplasmic trafficking is essential for BAK1- and BKK1-mediated cell-death control. Plant J. 85, 520-531.

Elias, J.E., and Gygi, S.P. (2007). Target-decoy search strategy for increased confidence in large-scale protein identifications by mass spectrometry. Nat Methods 4, 207-214.

Escocard de Azevedo Manhaes, A.M., Ortiz-Morea, F.A., He, P., and Shan, L. (2021). Plant plasma membrane-resident receptors: Surveillance for infections and coordination for growth and development. Journal of integrative plant biology 63, 79-101.

Faigon-Soverna, A., Harmon, F.G., Storani, L., Karayekov, E., Staneloni, R.J., Gassmann, W., Mas, P., Casal, J.J., Kay, S.A., and Yanovsky, M.J. (2006). A constitutive shade-avoidance mutant implicates TIR-NBS-LRR proteins in Arabidopsis photomorphogenic development. Plant Cell 18, 2919-2928.

Feys, B.J., Wiermer, M., Bhat, R.A., Moisan, L.J., Medina-Escobar, N., Neu, C., Cabral, A., and Parker, J.E. (2005). Arabidopsis SENESCENCE-ASSOCIATED GENE101 stabilizes and signals within an ENHANCED DISEASE SUSCEPTIBILITY1 complex in plant innate immunity. Plant Cell 17, 2601-2613.

Gao, M., Wang, X., Wang, D., Xu, F., Ding, X., Zhang, Z., Bi, D., Cheng, Y.T., Chen, S., Li, X., and Zhang, Y. (2009). Regulation of cell death and innate immunity by two receptor-like kinases in Arabidopsis. Cell Host Microbe 6, 34-44.

Gao, Y., Wu, Y., Du, J., Zhan, Y., Sun, D., Zhao, J., Zhang, S., Li, J., and He, K. (2017). Both LightInduced SA Accumulation and ETI Mediators Contribute to the Cell Death Regulated by BAK1 and BKK1. Front. Plant Sci. 8, 622.

Glazebrook, J., Rogers, E.E., and Ausubel, F.M. (1996). Isolation of Arabidopsis mutants with enhanced disease susceptibility by direct screening. Genetics 143, 973-982.

Gou, X., He, K., Yang, H., Yuan, T., Lin, H., Clouse, S.D., and Li, J. (2010). Genome-wide cloning and sequence analysis of leucine-rich repeat receptor-like protein kinase genes in Arabidopsis thaliana. BMC Genomics 11, 19.

Grefen, C., Obrdlik, P., and Harter, K. (2009). The determination of protein-protein interactions by the mating-based split-ubiquitin system (mbSUS). Methods Mol Biol 479, 217-233.

Grosseholz, R., Feldman-Salit, A., Wanke, F., Schulze, S., Glockner, N., Kemmerling, B., Harter, K., and Kummer, U. (2020). Specifying the role of BAK1-interacting receptor-like kinase 3 in brassinosteroid signaling. Journal of integrative plant biology 62, 456-469.

Halter, T., Imkampe, J., Mazzotta, S., Wierzba, M., Postel, S., Bücherl, C., Kiefer, C., Stahl, M., Chinchilla, D., Wang, X., Nürnberger, T., Zipfel, C., Clouse, S., Borst, J.W., Boeren, S., de Vries, S.C., Tax, F., and Kemmerling, B. (2014). The leucine-rich repeat receptor kinase BIR2 is a negative regulator of BAK1 in plant immunity. Curr. Biol. 24, 134-143.

He, K., Gou, X., Yuan, T., Lin, H., Asami, T., Yoshida, S., Russell, S.D., and Li, J. (2007). BAK1 and BKK1 regulate brassinosteroid-dependent growth and brassinosteroid-independent cell-death pathways. Curr. Biol. 17, 1109-1115.

Hecht, V., Vielle-Calzada, J.P., Hartog, M.V., Schmidt, E.D., Boutilier, K., Grossniklaus, U., and de Vries, S.C. (2001). The Arabidopsis SOMATIC EMBRYOGENESIS RECEPTOR KINASE 1 gene is expressed in developing ovules and embryos and enhances embryogenic competence in culture. Plant Physiol. 127, 803-816. 
Heese, A., Hann, D.R., Gimenez-Ibanez, S., Jones, A.M., He, K., Li, J., Schroeder, J.I., Peck, S.C., and Rathjen, J.P. (2007). The receptor-like kinase SERK3/BAK1 is a central regulator of innate immunity in plants. Proc. Natl. Acad. Sci. USA 104, 12217-12222.

Hohmann, U., Lau, K., and Hothorn, M. (2017). The Structural Basis of Ligand Perception and Signal Activation by Receptor Kinases. Annu. Rev. Plant Biol. 68, 109-137.

Hohmann, U., Nicolet, J., Moretti, A., Hothorn, L.A., and Hothorn, M. (2018). The SERK3 elongated allele defines a role for BIR ectodomains in brassinosteroid signalling. Nature Plants 4, 345351.

Hohmann, U., Ramakrishna, P., Wang, K., Lorenzo-Orts, L., Nicolet, J., Henschen, A., Barberon, M., Bayer, M., and Hothorn, M. (2020). Constitutive Activation of Leucine-Rich Repeat Receptor Kinase Signaling Pathways by BAK1-INTERACTING RECEPTOR-LIKE KINASE3 Chimera. Plant Cell 32, 3311-3323.

Imkampe, J., Halter, T., Huang, S., Schulze, S., Mazzotta, S., Schmidt, N., Manstretta, R., Postel, S., Wierzba, M., Yang, Y., van Dongen, W., Stahl, M., Zipfel, C., Goshe, M.B., Clouse, S., de Vries, S.C., Tax, F., Wang, X., and Kemmerling, B. (2017). The Arabidopsis Leucine-Rich Repeat Receptor Kinase BIR3 Negatively Regulates BAK1 Receptor Complex Formation and Stabilizes BAK1. Plant Cell 29, 2285-2303.

Jubic, L.M., Saile, S., Furzer, O.J., El Kasmi, F., and Dangl, J.L. (2019). Help wanted: helper NLRs and plant immune responses. Curr Opin Plant Biol 50, 82-94.

Karimi, M., Inze, D., and Depicker, A. (2002). GATEWAY(TM) vectors for Agrobacterium-mediated plant transformation. Trends Plant Sci. 7, 193-195.

Kelstrup, C.D., Jersie-Christensen, R.R., Batth, T.S., Arrey, T.N., Kuehn, A., Kellmann, M., and Olsen, J.V. (2014). Rapid and deep proteomes by faster sequencing on a benchtop quadrupole ultrahigh-field Orbitrap mass spectrometer. Journal of proteome research 13, 6187-6195.

Kemmerling, B., Schwedt, A., Rodriguez, P., Mazzotta, S., Frank, M., Qamar, S.A., Mengiste, T., Betsuyaku, S., Parker, J.E., Müssig, C., Thomma, B.P., Albrecht, C., de Vries, S.C., Hirt, H., and Nürnberger, T. (2007). The BRI1-associated kinase 1, BAK1, has a brassinolideindependent role in plant cell-death control. Curr. Biol. 17, 1116-1122.

Knepper, C., Savory, E.A., and Day, B. (2011). Arabidopsis NDR1 is an integrin-like protein with a role in fluid loss and plasma membrane-cell wall adhesion. Plant Physiol 156, 286-300.

Ladwig, F., Dahlke, R.I., Stührwohldt, N., Hartmann, J., Harter, K., and Sauter, M. (2015). Phytosulfokine Regulates Growth in Arabidopsis through a Response Module at the Plasma Membrane That Includes CYCLIC NUCLEOTIDE-GATED CHANNEL17, H+-ATPase, and BAK1. Plant Cell 27, 1718-1729.

Lapin, D., Bhandari, D.D., and Parker, J.E. (2020). Origins and Immunity Networking Functions of EDS1 Family Proteins. Annu Rev Phytopathol 58, 253-276.

Lenz, H.D., Haller, E., Melzer, E., Kober, K., Wurster, K., Stahl, M., Bassham, D.C., Vierstra, R.D., Parker, J.E., Bautor, J., Molina, A., Escudero, V., Shindo, T., van der Hoorn, R.A., Gust, A.A., and Nürnberger, T. (2011). Autophagy differentially controls plant basal immunity to biotrophic and necrotrophic pathogens. Plant J. 66, 818-830.

Li, J., Wen, J., Lease, K.A., Doke, J.T., Tax, F.E., and Walker, J.C. (2002). BAK1, an Arabidopsis LRR Receptor-like Protein Kinase, Interacts with BRI1 and Modulates Brassinosteroid Signaling. Cell 110, 213-222.

Li, L., Kim, P., Yu, L., Cai, G., Chen, S., Alfano, J.R., and Zhou, J.M. (2016). Activation-Dependent Destruction of a Co-receptor by a Pseudomonas syringae Effector Dampens Plant Immunity. Cell Host Microbe 20, 504-514.

Liebrand, T.W., van den Burg, H.A., and Joosten, M.H. (2014). Two for all: receptor-associated kinases SOBIR1 and BAK1. Trends Plant Sci. 19, 123-132.

Liu, Y., Huang, X., Li, M., He, P., and Zhang, Y. (2016). Loss-of-function of Arabidopsis receptor-like kinase BIR1 activates cell death and defense responses mediated by BAK1 and SOBIR1. New Phytol. 212, 637-645. 
Lolle, S., Stevens, D., and Coaker, G. (2020). Plant NLR-triggered immunity: from receptor activation to downstream signaling. Curr Opin Immunol 62, 99-105.

Lu, Y., and Tsuda, K. (2021). Intimate Association of PRR- and NLR-Mediated Signaling in Plant Immunity. Mol Plant Microbe Interact 34, 3-14.

Ma, C., Liu, Y., Bai, B., Han, Z., Tang, J., Zhang, H., Yaghmaiean, H., Zhang, Y., and Chai, J. (2017). Structural basis for BIR1-mediated negative regulation of plant immunity. Cell Res. 27, 15211524.

Mosher, S., Seybold, H., Rodriguez, P., Stahl, M., Davies, K.A., Dayaratne, S., Morillo, S.A., Wierzba, M., Favery, B., Keller, H., Tax, F.E., and Kemmerling, B. (2013). The tyrosine-sulfated peptide receptors PSKR1 and PSY1R modify the immunity of Arabidopsis to biotrophic and necrotrophic pathogens in an antagonistic manner. Plant J. 73, 469-482.

Nam, K.H., and Li, J. (2002). BRI1/BAK1, a Receptor Kinase Pair Mediating Brassinosteroid Signaling. Cell 110, 203-212.

Ngou, B.P.M., Ahn, H.K., Ding, P., and Jones, J.D.G. (2021). Mutual potentiation of plant immunity by cell-surface and intracellular receptors. Nature 592, 110-115.

Nour-Eldin, H.H., Geu-Flores, F., and Halkier, B.A. (2010). USER cloning and USER fusion: the ideal cloning techniques for small and big laboratories. Methods Mol Biol 643, 185-200.

Ordon, J., Gantner, J., Kemna, J., Schwalgun, L., Reschke, M., Streubel, J., Boch, J., and Stuttmann, J. (2017). Generation of chromosomal deletions in dicotyledonous plants employing a userfriendly genome editing toolkit. Plant J 89, 155-168.

Parkes, T. (2020). From Recognition to Susceptibility: Functional characterization of Plant- specific LIM-domain containing proteins in plant-microbe interactions. Thesis (PhD). University of Bath, Bath.

Rappsilber, J., Mann, M., and Ishihama, Y. (2007). Protocol for micro-purification, enrichment, prefractionation and storage of peptides for proteomics using StageTips. Nat Protoc 2, 18961906.

Redkar, A., Cevik, V., Bailey, K., Furzer, O.J., Fairhead, S., Borhan, M.H., Holub, E.B., and Jones, J.D.G. (2021). The Arabidopsis WRR4A and WRR4B paralogous NLR proteins both confer recognition of multiple Albugo candida effectors. bioRxiv, 2021.2003.2029.436918.

Roux, M., Schwessinger, B., Albrecht, C., Chinchilla, D., Jones, A., Holton, N., Malinovsky, F.G., Tor, M., de Vries, S., and Zipfel, C. (2011). The Arabidopsis leucine-rich repeat receptor-like kinases BAK1/SERK3 and BKK1/SERK4 are required for innate immunity to hemibiotrophic and biotrophic pathogens. Plant Cell 23, 2440-2455.

Santiago, J., Henzler, C., and Hothorn, M. (2013). Molecular mechanism for plant steroid receptor activation by somatic embryogenesis co-receptor kinases. Science 341, 889-892.

Saur, I.M.L., Panstruga, R., and Schulze-Lefert, P. (2020). NOD-like receptor-mediated plant immunity: from structure to cell death. Nature reviews. Immunology.

Schulze, B., Mentzel, T., Jehle, A.K., Mueller, K., Beeler, S., Boller, T., Felix, G., and Chinchilla, D. (2010). Rapid heteromerization and phosphorylation of ligand-activated plant transmembrane receptors and their associated kinase BAK1. J. Biol. Chem. 285, 9444-9451.

Schwessinger, B., Roux, M., Kadota, Y., Ntoukakis, V., Sklenar, J., Jones, A., and Zipfel, C. (2011). Phosphorylation-dependent differential regulation of plant growth, cell death, and innate immunity by the regulatory receptor-like kinase BAK1. PLoS Genet. 7, e1002046.

Shan, L., He, P., Li, J., Heese, A., Peck, S.C., Nürnberger, T., Martin, G.B., and Sheen, J. (2008). Bacterial effectors target the common signaling partner BAK1 to disrupt multiple MAMP receptor-signaling complexes and impede plant immunity. Cell Host Microbe 4, 17-27.

Shiu, S.H., and Bleecker, A.B. (2001). Receptor-like kinases from Arabidopsis form a monophyletic gene family related to animal receptor kinases. Proc. Natl. Acad. Sci. USA 98, 10763-10768.

Song, W., Han, Z., Wang, J., Lin, G., and Chai, J. (2016). Structural insights into ligand recognition and activation of plant receptor kinases. Curr. Opin. Struct. Biol. 43, 18-27. 
Stegmann, M., Monaghan, J., Smakowska-Luzan, E., Rovenich, H., Lehner, A., Holton, N., Belkhadir, Y., and Zipfel, C. (2017). The receptor kinase FER is a RALF-regulated scaffold controlling plant immune signaling. Science 355, 287-289.

Sun, T., Zhang, Q., Gao, M., and Zhang, Y. (2014). Regulation of SOBIR1 accumulation and activation of defense responses in bir1-1 by specific components of ER quality control. Plant J. 77, 748756.

Sun, X., Lapin, D., Feehan, J.M., Stolze, S.C., Kramer, K., Dongus, J.M., Rzemieniewski, J., BlanvillainBaufumé, S., Harzen, A., Bautor, J., Derbyshire, P., Menke, F.L.H., Finkemeier, I., Nakagami, H., Jones, J.D.G., and Parker, J.E. (2020). Pathogen effector recognition-dependent association of NRG1 with EDS1 and SAG101 in TNL receptor immunity. BioRxiv, 10.1101/2020.1112.1121.423810

Sun, Y., Han, Z., Tang, J., Hu, Z., Chai, C., Zhou, B., and Chai, J. (2013a). Structure reveals that BAK1 as a co-receptor recognizes the BRI1-bound brassinolide. Cell Res. 23, 1326-1329.

Sun, Y., Li, L., Macho, A.P., Han, Z., Hu, Z., Zipfel, C., Zhou, J.M., and Chai, J. (2013b). Structural Basis for flg22-Induced Activation of the Arabidopsis FLS2-BAK1 Immune Complex. Science 342, 624-628.

Van de Weyer, A.L., Monteiro, F., Furzer, O.J., Nishimura, M.T., Cevik, V., Witek, K., Jones, J.D.G., Dangl, J.L., Weigel, D., and Bemm, F. (2019). A Species-Wide Inventory of NLR Genes and Alleles in Arabidopsis thaliana. Cell 178, 1260-1272 e1214.

Van der Does, D., Boutrot, F., Engelsdorf, T., Rhodes, J., McKenna, J.F., Vernhettes, S., Koevoets, I., Tintor, N., Veerabagu, M., Miedes, E., Segonzac, C., Roux, M., Breda, A.S., Hardtke, C.S., Molina, A., Rep, M., Testerink, C., Mouille, G., Hofte, H., Hamann, T., and Zipfel, C. (2017). The Arabidopsis leucine-rich repeat receptor kinase MIK2/LRR-KISS connects cell wall integrity sensing, root growth and response to abiotic and biotic stresses. PLoS Genet 13, e1006832.

Wan, W.L., Zhang, L., Pruitt, R., Zaidem, M., Brugman, R., Ma, X., Krol, E., Perraki, A., Kilian, J., Grossmann, G., Stahl, M., Shan, L., Zipfel, C., van Kan, J.A.L., Hedrich, R., Weigel, D., Gust, A.A., and Nurnberger, T. (2019). Comparing Arabidopsis receptor kinase and receptor protein-mediated immune signaling reveals BIK1-dependent differences. New Phytol 221, 2080-2095.

Wang, X., Kota, U., He, K., Blackburn, K., Li, J., Goshe, M.B., Huber, S.C., and Clouse, S.D. (2008). Sequential transphosphorylation of the BRI1/BAK1 receptor kinase complex impacts early events in brassinosteroid signaling. Dev. Cell 15, 220-235.

Williams, S.J., Sohn, K.H., Wan, L., Bernoux, M., Sarris, P.F., Segonzac, C., Ve, T., Ma, Y., Saucet, S.B., Ericsson, D.J., Casey, L.W., Lonhienne, T., Winzor, D.J., Zhang, X., Coerdt, A., Parker, J.E., Dodds, P.N., Kobe, B., and Jones, J.D. (2014). Structural basis for assembly and function of a heterodimeric plant immune receptor. Science 344, 299-303.

Wu, Y., Gao, Y., Zhan, Y., Kui, H., Liu, H., Yan, L., Kemmerling, B., Zhou, J.M., He, K., and Li, J. (2020). Loss of the common immune coreceptor BAK1 leads to NLR-dependent cell death. Proc Natl Acad Sci U S A 117, 27044-27053.

Wu, Z., Li, M., Dong, O.X., Xia, S., Liang, W., Bao, Y., Wasteneys, G., and Li, X. (2019). Differential regulation of TNL-mediated immune signaling by redundant helper CNLs. New Phytol 222, 938-953.

Xing, W., Zou, Y., Liu, Q., Liu, J., Luo, X., Huang, Q., Chen, S., Zhu, L., Bi, R., Hao, Q., Wu, J.W., Zhou, J.M., and Chai, J. (2007). The structural basis for activation of plant immunity by bacterial effector protein AvrPto. Nature 449, 243-247.

Xu, F., Zhu, C., Cevik, V., Johnson, K., Liu, Y., Sohn, K., Jones, J.D., Holub, E.B., and Li, X. (2015). Autoimmunity conferred by chs3-2D relies on CSA1, its adjacent TNL-encoding neighbour. Sci. Rep. 5, 8792.

Yamada, K., Yamashita-Yamada, M., Hirase, T., Fujiwara, T., Tsuda, K., Hiruma, K., and Saijo, Y. (2016). Danger peptide receptor signaling in plants ensures basal immunity upon pathogeninduced depletion of BAK1. EMBO J. 35, 46-61. 
Yang, H., Shi, Y., Liu, J., Guo, L., Zhang, X., and Yang, S. (2010). A mutant CHS3 protein with TIR-NBLRR-LIM domains modulates growth, cell death and freezing tolerance in a temperaturedependent manner in Arabidopsis. Plant J 63, 283-296.

Yu, X., Xu, G., Li, B., de Souza Vespoli, L., Liu, H., Moeder, W., Chen, S., de Oliveira, M.V.V., Ariadina de Souza, S., Shao, W., Rodrigues, B., Ma, Y., Chhajed, S., Xue, S., Berkowitz, G.A., Yoshioka, K., He, P., and Shan, L. (2019). The Receptor Kinases BAK1/SERK4 Regulate Ca(2+) Channel-Mediated Cellular Homeostasis for Cell Death Containment. Current biology : CB 29, 3778-3790 e3778.

Yuan, M., Jiang, Z., Bi, G., Nomura, K., Liu, M., Wang, Y., Cai, B., Zhou, J.M., He, S.Y., and Xin, X.F. (2021). Pattern-recognition receptors are required for NLR-mediated plant immunity. Nature 592, 105-109.

Zhang, Y., and Li, X. (2005). A putative nucleoporin 96 Is required for both basal defense and constitutive resistance responses mediated by suppressor of npr1-1, constitutive 1. Plant Cell $17,1306-1316$.

Zhou, J., Wu, S., Chen, X., Liu, C., Sheen, J., Shan, L., and He, P. (2014). The Pseudomonas syringae effector HopF2 suppresses Arabidopsis immunity by targeting BAK1. Plant J 77, 235-245.

Zhou, Z., Bi, G., and Zhou, J.M. (2018). Luciferase Complementation Assay for Protein-Protein Interactions in Plants. Curr Protoc Plant Biol 3, 42-50.

\section{Acknowledgements}

This study was supported by the DFG SFB1101 D03 project to B.K. and DFG SFB1101 D09 project to F.E.K. We thank Silke Wahl and Irina Droste-Borel for technical support for the proteomics assays, J.-M. Zhou for providing Split-Luc vectors and Thorsten Nürnberger for critical reading of the manuscript.

\section{Author Contributions}

SS and LY designed research, performed research and analyzed data; AE, DK, MFW and MS performed research and analyzed data; SCS performed research, analyzed data and designed research; LL provided materials for this research; FEK analyzed data, designed research and provided materials for this research, VC designed research and provided materials for this research and BK designed research, analyzed data and wrote the manuscript. All authors revised the manuscript.

\section{Competing Interests statement}

The authors declare no competing interests.

\section{Figure Legends}


Figure 1: Loss-of EDS1 can partially block bak1 bir3 induced cell death.

(A) Representative pictures of the morphological phenotypes of 6-week-old Col-0, bir3-2, bak1-4, eds1-12, the double mutant bak1-4 bir3-2 and the triple mutant bak1-4 bir3-2 eds112 are shown. (B) Alternaria brassicicola droplet-infected leaves of the genotypes shown in (A) 13 days after inoculation. (C) Leaves of the same genotypes as in (A) and (B) dropletinfected with Alternaria brassicicola and trypan blue stained. The scale bar in (A), (B) and (C) represents $10 \mathrm{~mm}$. (D) Disease indices of Alternaria brassicicola infected leaves of the indicated genotypes 13 days after infection shown as mean $\pm S E(n=12)$. Different letters indicate significant differences according to one-way ANOVA and Tukey's HSD test $(p<0.05)$. The experiments were repeated at least three times with similar results.

\section{Figure 2: CSA1 can interact with BIR3}

(A) Western Blots after co-immunoprecipitation with GFP-traps of transiently in $N$. benthamiana expressed BIR3-eGFP and CSA1-V 5 detected with $\alpha$-GFP and $\alpha$-V 5 antibodies are shown. Protein input is shown by Western blot analyses of protein extracts before IP with antibodies against the respective tags. p19 is a silencing inhibitor expressed alone as a background control. Ponceau $S$ staining shows protein loading. Dotted lines indicate cut and rearranged parts of the same blot. (B) Split-Luciferase assays with transiently expressed BIR3-Nluc and CSA1-Cluc fusion proteins show reconstituted luciferase activity measured in relative light units (RLU) indicating that the two proteins are in close vicinity. BAK1-Nluc and BIR3-Cluc constructs serve as positive controls. Empty vector controls (PNL, PCL) serve as negative controls. (C) Split-ubiquitin yeast growth assays containing the two indicated proteins fused to $\mathrm{N}$ - and C-terminal parts of ubiquitin were performed (ev, empty vector). Yeast was grown at three different 1 to 10 dilutions on medium selecting for vector transformation (CSM - $\mathrm{Leu}^{-}, \mathrm{Trp}^{-}$) and for interaction (CSM-Leu', $\mathrm{Trp}^{-}, \mathrm{Ade}^{-}, \mathrm{His}^{-}$). Growth was monitored after $1 \mathrm{~d}$ for the vector-selective control plates and after $3 \mathrm{~d}$ for the interaction plates. BIR3 and BAK1 serve as positive controls, empty vector controls as negative controls. All experiments were repeated at least three times with similar results.

Figure 3: The CSA1 partner CHS3 resides in the BIR3 complex but does not directly interact with BIR3

(A) Western Blots after co-immunoprecipitation with GFP-traps of transiently in $N$. benthamiana expressed BIR3-eGFP and CHS3-V5 protein detected with $\alpha$-GFP and $\alpha$-V5 antibodies are shown. Protein input is shown by Western blot analysis of protein extracts before IP with antibodies against the respective tags. p19 is a silencing inhibitor expressed alone as a background control. Ponceau S staining shows protein loading. Dotted lines 
indicate cut and rearranged parts of the same blot. (B) Split-Luc assays with transiently expressed BIR3-Nluc and CHS3-Cluc fusion proteins were analyzed for reconstituted luciferase activity measured in relative light units (RLU). BAK1-Nluc and BIR3-Cluc constructs serve as positive controls. Empty vector controls (PNL, PCL) serve as negative controls. Different letters indicate significant differences according to one-way ANOVA and Tukey's HSD test $(p<0.05)$. (C) Split-ubiquitin yeast growth assays containing the two indicated proteins fused to $\mathrm{N}$ - and $\mathrm{C}$-terminal parts of ubiquitin were performed (ev, empty vector). Yeast was grown at three different 1 to 10 dilutions on medium selecting for vector transformation (CSM -Leu-, Trp ${ }^{-}$) and for interaction (CSM-Leu ${ }^{-}, \mathrm{Trp}^{-}, \mathrm{Ade}^{-}$, $\mathrm{His}^{-}$). Growth was monitored after $1 \mathrm{~d}$ for the vector-selective control plates and after $3 \mathrm{~d}$ for the interaction plates. BIR3 and BAK1 serve as positive controls, empty vector controls as negative controls. All experiments were repeated at least three times with similar results.

\section{Figure 4: CSA1 is in the same complex with BAK1 but the interaction is not direct}

(A) Western Blots after co-immunoprecipitation with GFP-traps of transiently in $N$. benthamiana expressed BAK1-eGFP and CSA1-V5 detected with $\alpha$-GFP and $\alpha$-V5 antibodies are shown. Protein input is shown by Western blot analysis of protein extracts before IP with antibodies against the respective tags. p19 is a silencing inhibitor expressed alone as a background control. Ponceau $S$ staining shows protein loading. Dotted lines indicate cut and rearranged parts of the same blot. (B) Split-Luc assays with transiently expressed BAK1-Nluc and CSA1-Cluc fusion proteins were analyzed for reconstituted luciferase activity measured in relative light units (RLU). BAK1-Nluc and BIR3-Cluc constructs serve as positive controls. Empty vector controls (PNL, PCL) serve as negative controls. Different letters indicate significant differences according to one-way ANOVA and Tukey's HSD test $(p<0.05)$. (C) Split-ubiquitin yeast growth assays containing the two indicated proteins fused to $\mathrm{N}$ - and $\mathrm{C}$-terminal parts of ubiquitin were performed (ev, empty vector). Yeast was grown at three different 1 to 10 dilutions on medium selecting for vector transformation (CSM -Leu-, Trp ${ }^{-}$) and for interaction (CSM-Leu ${ }^{-}, \mathrm{Trp}^{-}, \mathrm{Ade}^{-}, \mathrm{His}^{-}$). Growth was monitored after $1 \mathrm{~d}$ for the vector-selective control plates and after $3 \mathrm{~d}$ for the interaction plates. BIR3 and BAK1 serve as positive controls, empty vector controls as negative controls. All experiments were repeated at least three times with similar results.

\section{Figure 5: CHS3 is in the same complex with BAK1 but the interaction is not direct}

(A) Western Blots after co-immunoprecipitation with GFP-traps of transiently in $N$. benthamiana expressed BAK1-eGFP and CHS3-V5 detected with $\alpha$-GFP and $\alpha$-V5 antibodies are shown. Protein input is shown by Western blot analysis of protein extracts 
before IP with antibodies against the respective tags. p19 is a silencing inhibitor expressed alone as a background control. Ponceau $S$ staining shows protein loading. Dotted lines indicate cut and rearranged parts of the same blot. (B) Split-Luc assays with transiently expressed BAK1-Nluc and CHS3-Cluc fusion proteins were analyzed for reconstituted luciferase activity measured in relative light units (RLU). BAK1-Nluc and BIR3-Cluc constructs serve as positive controls. Empty vector controls (PNL, PCL) serve as negative controls. Different letters indicate significant differences according to one-way ANOVA and Tukey's HSD test $(p<0.05)$. (C) Split-ubiquitin yeast growth assays containing the two indicated proteins fused to $\mathrm{N}$ - and $\mathrm{C}$-terminal parts of ubiquitin were performed (ev, empty vector). Yeast was grown at three different 1 to 10 dilutions on medium selecting for vector transformation (CSM -Leu-, Trp ${ }^{-}$) and for interaction (CSM-Leu ${ }^{-}, \mathrm{Trp}^{-}, \mathrm{Ade}^{-}$, $\mathrm{His}^{-}$). Growth was monitored after $1 \mathrm{~d}$ for the vector-selective control plates and after $3 \mathrm{~d}$ for the interaction plates. BIR3 and BAK1 serve as positive controls, empty vector controls as negative controls. All experiments were repeated at least three times with similar results.

\section{Figure 6: CSA1 is necessary for bak1 bir3-mediated cell death}

A) Representative pictures of the morphological phenotypes of 6-week-old plants of the indicated genotypes are shown. (B) Alternaria brassicicola infected leaves of the genotypes shown in (A) 13 days after inoculation. (C) Infected leaves of the genotypes shown in (A, B) stained with trypan blue for cell death. The scale bar in (A), (B) and (C) represents $10 \mathrm{~mm}$. (D) Disease indices of Alternaria brassicicola infected leaves of the indicated genotypes 13 days after infection shown as mean $\pm S E(n=12)$. (E) Total salicylic acid levels measured in untreated leaf material of plants of the indicated genotypes relative to the fresh weight. (F) ROS production was measured as relative light units $(R L U)$ in a luminol based assay. Leaf pieces of plants of the indicated genotypes were elicited with $100 \mathrm{nM}$ flg22 and ROS production was measured over a period of $30 \mathrm{~min}$. Values are mean $\pm \mathrm{SE}(\mathrm{n}=9)$. (G) FRK1 marker gene expression in leaves of plants of the indicated genotypes was measured by qRT-PCR analysis 3 hours after $100 \mathrm{nM}$ flg22 or mock treatment. FRK1 expression was normalized to EF1a. Results are mean \pm SE $(n=9)$. Different letters indicate significant differences according to one-way ANOVA and Tukey's HSD test $(p<0.05)$. The experiments were repeated at least three times with similar results.

Figure 7: CSA1 is necessary for bak1-mediated cell death but not for flg22 responses.

A) Representative pictures of the morphological phenotype of 6-week-old plants of the indicated genotypes are shown. (B) Alternaria brassicicola infected leaves of the genotypes shown in (A) 13 days after inoculation. (C) Infected leaves of the genotypes shown in (A) stained with trypan blue for cell death. The scale bar in $(A),(B)$ and $(C)$ represents $10 \mathrm{~mm}$. 
(D) Disease indices of Alternaria brassicicola infected leaves of the indicated genotypes 13 days after infection shown as mean \pm SE $(n=12)$. (E) Total salicylic acid levels measured in untreated leaf material of plants of the indicated genotypes relative to the fresh weight. (F) ROS production was measured as relative light units $(R L U)$ in a luminol based assay. Leaf pieces of plants of the indicated genotypes were elicited with $100 \mathrm{nM}$ flg22 and ROS production was measured over a period of $30 \mathrm{~min}$. Values are mean $\pm \mathrm{SE}(\mathrm{n}=9)$. (G) FRK1 marker gene expression in leaves of plants of the indicated genotypes was measured by qRT-PCR analysis 3 hours after $100 \mathrm{nM}$ flg22 or mock treatment. FRK1 expression was normalized to EF1a. Results are mean \pm SE $(n=9)$. Different letters indicate significant differences according to one-way ANOVA and Tukey's HSD test $(p<0.05)$. The experiments were repeated at least three times with similar results.

\section{Supplemental Tables}

Supplemental Table1: BIR3 interacting RKs.xls

Supplemental Table 2: Primers used in this study

\section{Supplemental Figure titles}

Supplemental Figure1. Reduced SA levels by NahG expression and mutation in PAD4 and SAG101 can weakly suppress the dwarf phenotype of bak1 bir3 mutants

Supplemental Figure 2: Helper NLRs NRG1-1 and NRG1-2 are necessary for bak1-4bir3-2 double mutant phenotype

Supplemental Figure 3: Mass spectrometric identification of the BIR3 interacting protein CSA1

Supplemental Figure 4: CSA1 can interact with BIR1 and BIR2

Supplemental Figure 5: CSA1 localizes preferentially to microsomal fractions

Supplemental Figure 6: Expression controls for Split-luciferase assays

Supplemental Figure 7: Expression controls for Split-ubiquitin assays 
Supplemental Figure 8: Sequence and domain structure of $\mathrm{CHS3}$

Supplemental Figure 9: CHS3 can interact with BIR1 and BIR2

Supplemental Figure 10: CSA1 is not sufficient to suppress bir1-mediated dwarfism

Supplemental Figure 11. Mutation in chs3 partially suppresses cell death phenotypes in bak1 bir3 double mutants

Supplemental Figure 12: Expression of CSA1 can complement the bak1 bir3 csa1 triple mutant phenotype

Supplemental Figure 13: Expression of CSA1 can complement the bak 1 csa1 double mutant phenotype 
A
Col-0
bir3-2
bak1-4 eds1-12
bir3-2

bir3-2

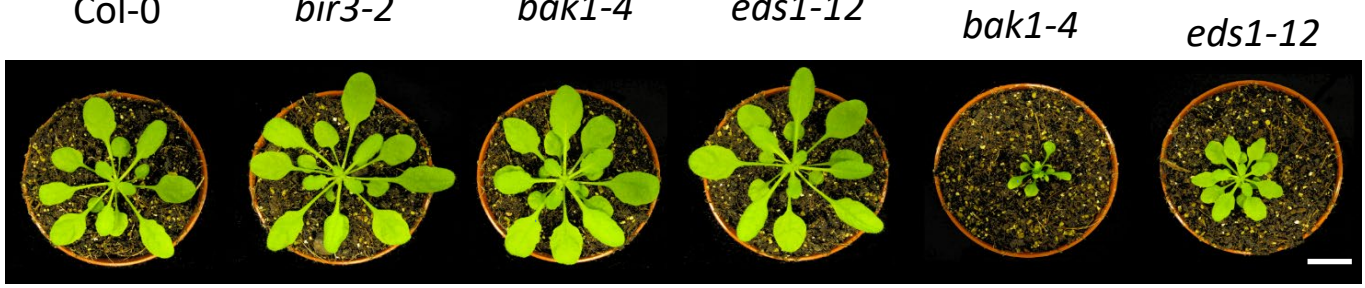

B

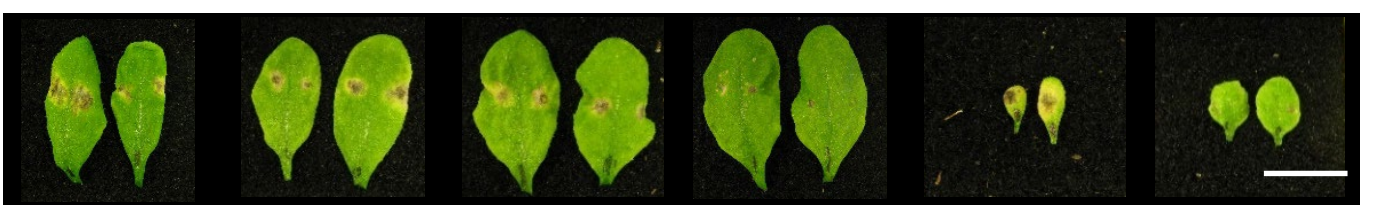

C

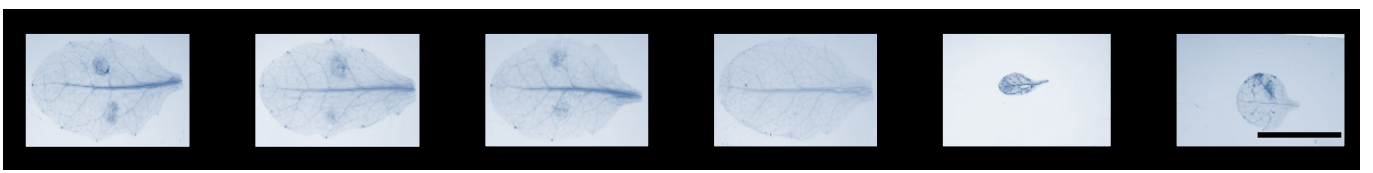

D

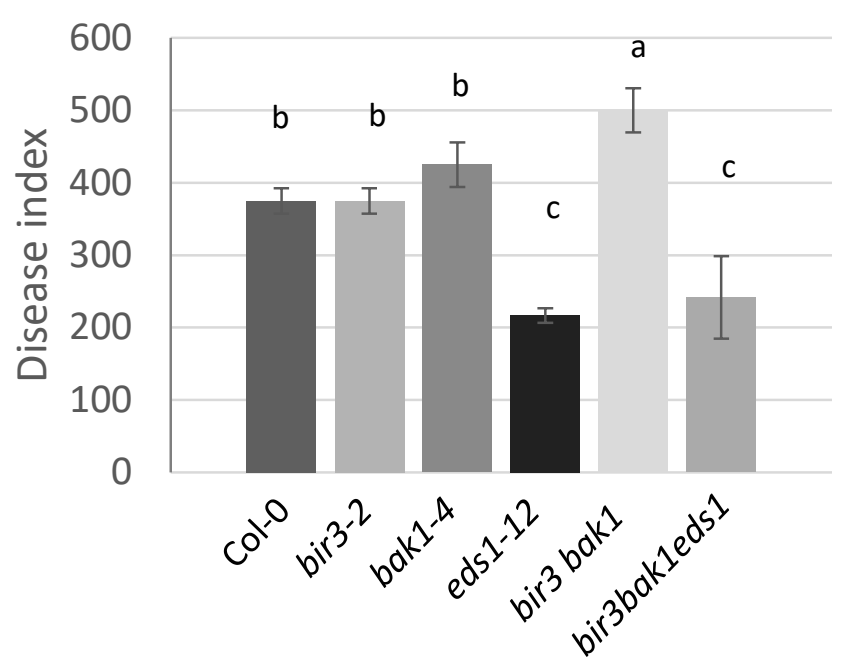

Figure 1: Loss-of EDS1 can partially block bak1 bir3 induced cell death.

(A) Representative pictures of the morphological phenotypes of 6-week-old Col-0, bir3-2, bak1-4, eds1-12, the double mutant bak1-4 bir3-2 and the triple mutant bak1-4 bir3-2 eds1-12 are shown. (B) Alternaria brassicicola droplet-infected leaves of the genotypes shown in (A) 13 days after inoculation. (C) Leaves of the same genotypes as in (A) and (B) droplet-infected with Alternaria brassicicola and trypan blue stained. The scale bar in (A), (B) and (C) represents $10 \mathrm{~mm}$. (D) Disease indices of Alternaria brassicicola infected leaves of the indicated genotypes 13 days after infection shown as mean $\pm S E(n=12)$. Different letters indicate significant differences according to one-way ANOVA and Tukey's HSD test $(p<0.05)$. The experiments were repeated at least three times with similar results. 


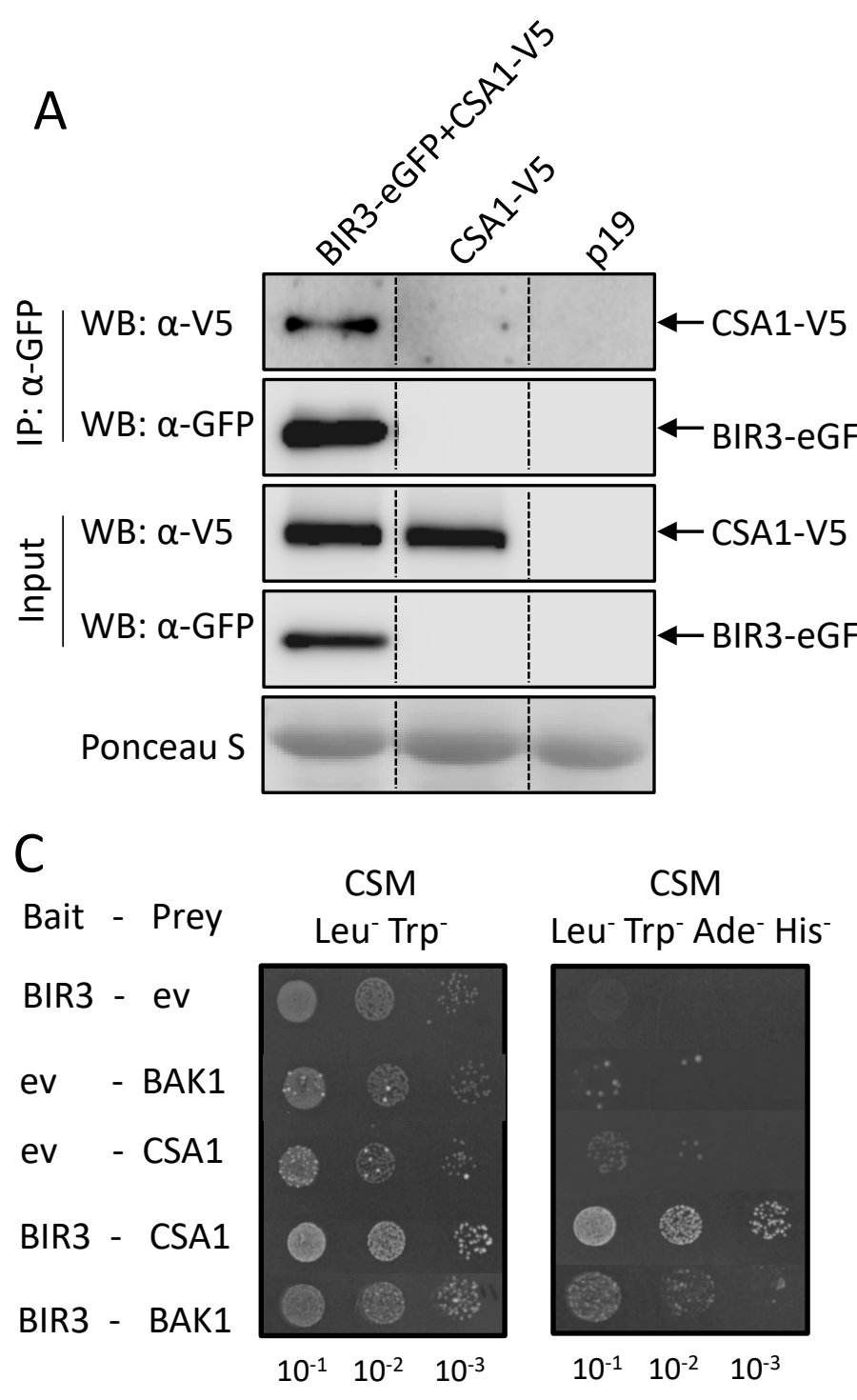

B

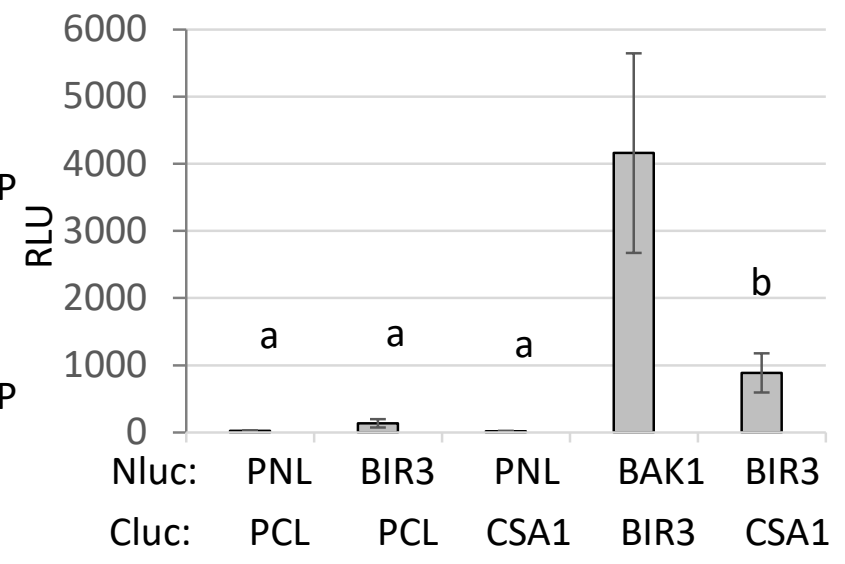

Figure 2: CSA1 can interact with BIR3

(A) Western Blots after co-immunoprecipitation with GFP-traps of transiently in N. benthamiana expressed BIR3-eGFP and CSA1-V5 detected with $\alpha$-GFP and $\alpha-V 5$ antibodies are shown. Protein input is shown by Western blot analyses of protein extracts before IP with antibodies against the respective tags. p19 is a silencing inhibitor expressed alone as a background control. Ponceau S staining shows protein loading. Dotted lines indicate cut and rearranged parts of the same blot. (B) Split-Luciferase assays with transiently expressed BIR3-Nluc and CSA1-Cluc fusion proteins show reconstituted luciferase activity measured in relative light units $(R L U)$ indicating that the two proteins are in close vicinity. BAK1-Nluc and BIR3-Cluc constructs serve as positive controls. Empty vector controls (PNL, PCL) serve as negative controls. (C) Split-ubiquitin yeast growth assays containing the two indicated proteins fused to $\mathrm{N}$ - and $\mathrm{C}$-terminal parts of ubiquitin were performed (ev, empty vector). Yeast was grown at three different 1 to 10 dilutions on medium selecting for vector transformation (CSM - $\left.\mathrm{Leu}^{-}, \mathrm{Trp}^{-}\right)$and for interaction (CSM-Leu ${ }^{-}, \mathrm{Trp}^{-}, \mathrm{Ade}^{-}$, $\left.\mathrm{His}^{-}\right)$. Growth was monitored after $1 \mathrm{~d}$ for the vector-selective control plates and after $3 \mathrm{~d}$ for the interaction plates. BIR3 and BAK1 serve as positive controls, empty vector controls as negative controls. All experiments were repeated at least three times with similar results. 


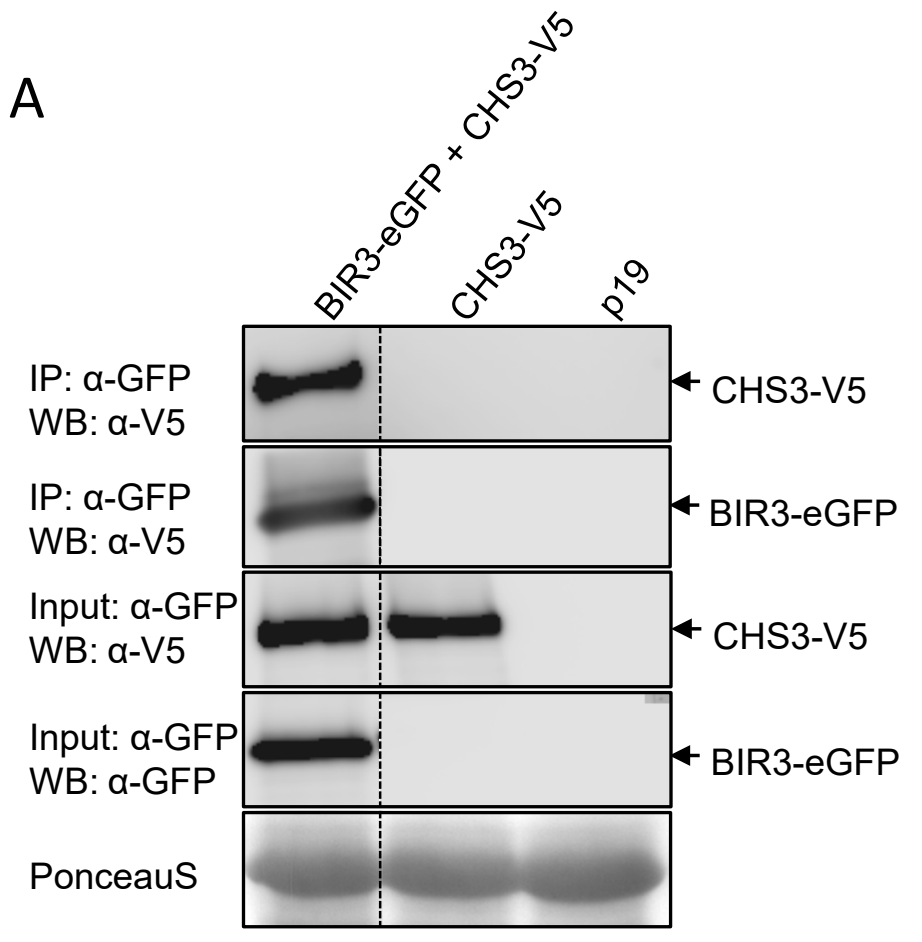

B

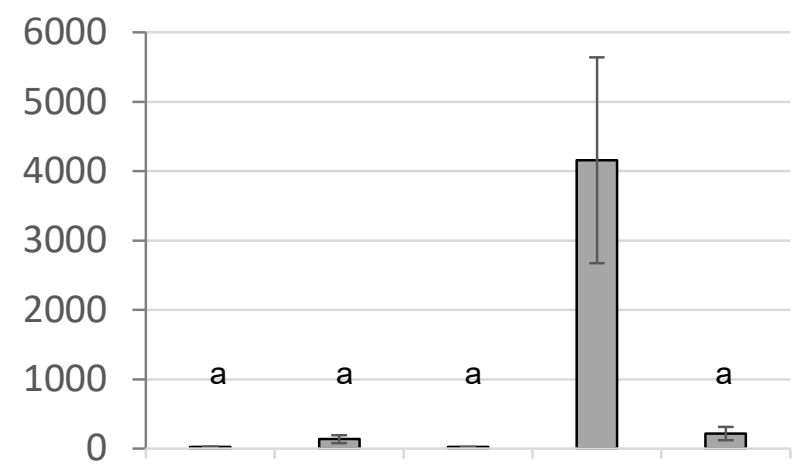

Nluc: PNL BIR3 PNL BAK1 BIR3

Cluc: $\mathrm{PCL} \quad \mathrm{PCL} \quad \mathrm{CHS3} \quad \mathrm{BIR} 3 \quad \mathrm{CHS} 3$

C

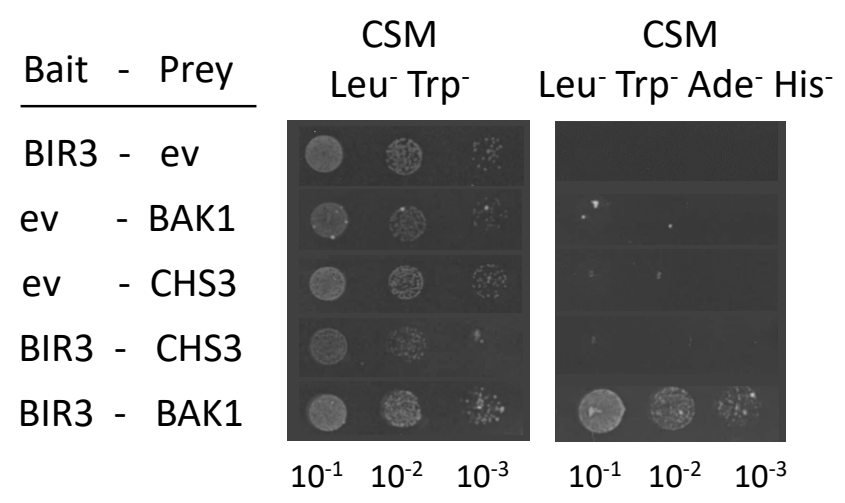

Figure 3: The CSA1 partner CHS3 resides in the BIR3 complex but does not directly interact with BIR3

(A) Western Blots after co-immunoprecipitation with GFP-traps of transiently in $N$. benthamiana expressed BIR3-eGFP and CHS3-V5 protein detected with $\alpha$-GFP and $\alpha-\mathrm{V} 5$ antibodies are shown. Protein input is shown by Western blot analysis of protein extracts before IP with antibodies against the respective tags. p19 is a silencing inhibitor expressed alone as a background control. Ponceau S staining shows protein loading. Dotted lines indicate cut and rearranged parts of the same blot. (B) Split-Luc assays with transiently expressed BIR3-Nluc and CHS3-Cluc fusion proteins were analyzed for reconstituted luciferase activity measured in relative light units (RLU). BAK1-Nluc and BIR3-Cluc constructs serve as positive controls. Empty vector controls (PNL, PCL) serve as negative controls. Different letters indicate significant differences according to one-way ANOVA and Tukey's HSD test $(p<0.05)$. (C) Split-ubiquitin yeast growth assays containing the two indicated proteins fused to $\mathrm{N}$ - and $\mathrm{C}$-terminal parts of ubiquitin were performed (ev, empty vector). Yeast was grown at three different 1 to 10 dilutions on medium selecting for vector transformation (CSM - $\left.\mathrm{Leu}^{-}, \mathrm{Trp}^{-}\right)$and for interaction (CSM-Leu ${ }^{-}$, Trp $^{-}$, Ade $^{-}, \mathrm{His}^{-}$). Growth was monitored after $1 \mathrm{~d}$ for the vector-selective control plates and after $3 \mathrm{~d}$ for the interaction plates. BIR3 and BAK1 serve as positive controls, empty vector controls as negative controls. All experiments were repeated at least three times with similar results. 


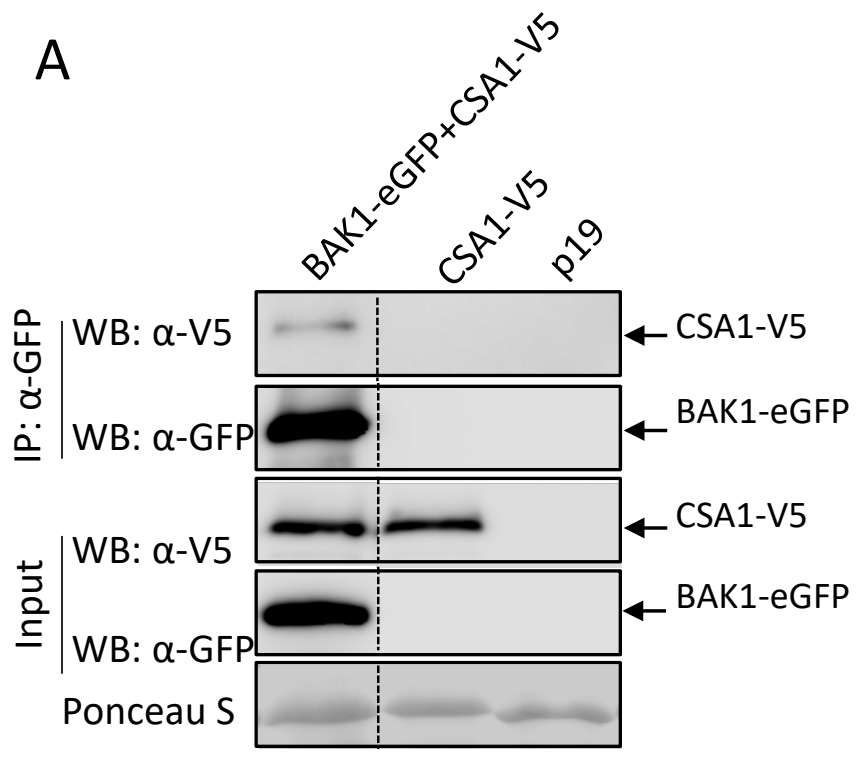

B
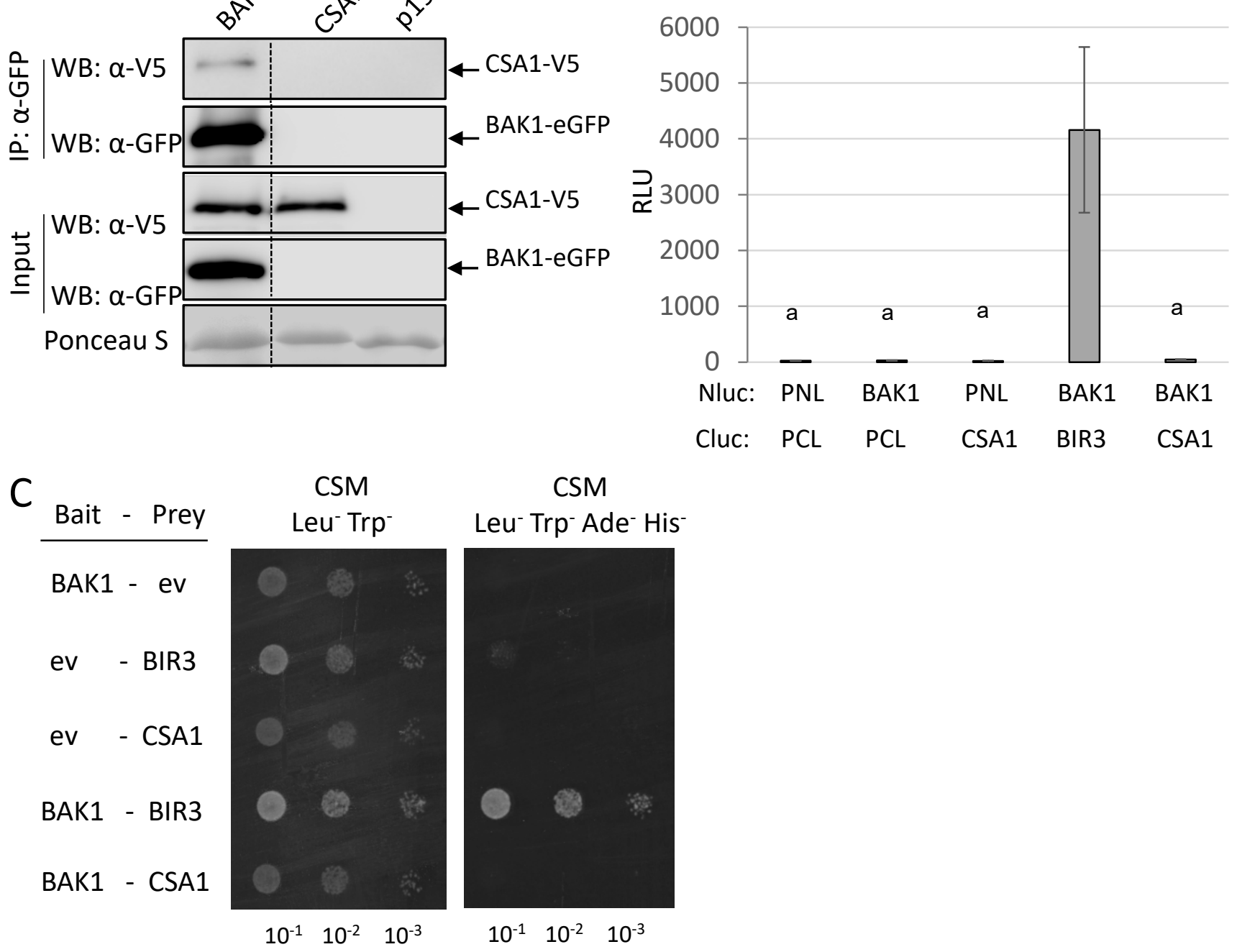

Figure 4: CSA1 is in the same complex with BAK1 but the interaction is not direct

(A) Western Blots after co-immunoprecipitation with GFP-traps of transiently in $N$. benthamiana expressed BAK1-eGFP and CSA1-V5 detected with $\alpha$-GFP and $\alpha-V 5$ antibodies are shown. Protein input is shown by Western blot analysis of protein extracts before IP with antibodies against the respective tags. p19 is a silencing inhibitor expressed alone as a background control. Ponceau $S$ staining shows protein loading. Dotted lines indicate cut and rearranged parts of the same blot. (B) Split-Luc assays with transiently expressed BAK1-Nluc and CSA1-Cluc fusion proteins were analyzed for reconstituted luciferase activity measured in relative light units (RLU). BAK1-Nluc and BIR3-Cluc constructs serve as positive controls. Empty vector controls (PNL, PCL) serve as negative controls. Different letters indicate significant differences according to one-way ANOVA and Tukey's HSD test $(p<0.05)$. (C) Split-ubiquitin yeast growth assays containing the two indicated proteins fused to $\mathrm{N}$ - and $\mathrm{C}$-terminal parts of ubiquitin were performed (ev, empty vector). Yeast was grown at three different 1 to 10 dilutions on medium selecting for vector transformation (CSM -Leu' ${ }^{-}, \mathrm{Trp}^{-}$) and for interaction (CSM-Leu ${ }^{-}, \mathrm{Trp}^{-}, \mathrm{Ade}^{-}, \mathrm{His}^{-}$). Growth was monitored after $1 \mathrm{~d}$ for the vector-selective control plates and after $3 \mathrm{~d}$ for the interaction plates. BIR3 and BAK1 serve as positive controls, empty vector controls as negative controls. All experiments were repeated at least three times with similar results. 


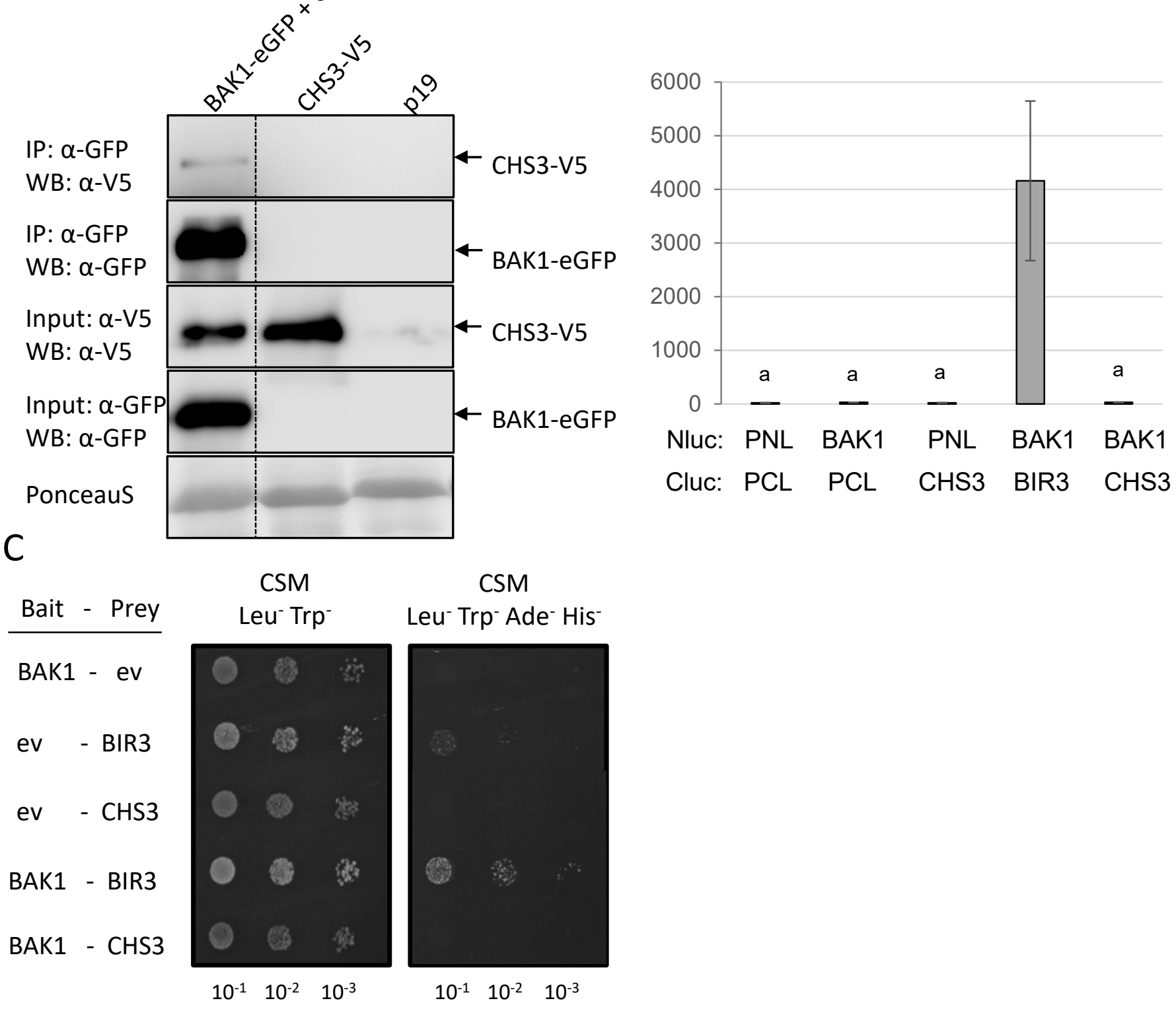

Figure 5: CHS3 is in the same complex with BAK1 but the interaction is not direct

(A) Western Blots after co-immunoprecipitation with GFP-traps of transiently in $N$. benthamiana expressed BAK1-eGFP and CHS3-V5 detected with $\alpha$-GFP and $\alpha$-V 5 antibodies are shown. Protein input is shown by Western blot analysis of protein extracts before IP with antibodies against the respective tags. $p 19$ is a silencing inhibitor expressed alone as a background control. Ponceau $S$ staining shows protein loading. Dotted lines indicate cut and rearranged parts of the same blot. (B) Split-Luc assays with transiently expressed BAK1-Nluc and CHS3-Cluc fusion proteins were analyzed for reconstituted luciferase activity measured in relative light units (RLU). BAK1-Nluc and BIR3-Cluc constructs serve as positive controls. Empty vector controls (PNL, PCL) serve as negative controls. Different letters indicate significant differences according to one-way ANOVA and Tukey's HSD test $(p<0.05)$. (C) Split-ubiquitin yeast growth assays containing the two indicated proteins fused to $\mathrm{N}$ - and $\mathrm{C}$-terminal parts of ubiquitin were performed (ev, empty vector). Yeast was grown at three different 1 to 10 dilutions on medium selecting for vector transformation (CSM -Leu', $\left.\mathrm{Trp}^{-}\right)$and for interaction (CSM-Leu $\left.{ }^{-}, \mathrm{Trp}^{-}, \mathrm{Ade}^{-}, \mathrm{His}^{-}\right)$. Growth was monitored after $1 \mathrm{~d}$ for the vector-selective control plates and after $3 \mathrm{~d}$ for the interaction plates. BIR3 and BAK1 serve as positive controls, empty vector controls as negative controls. All experiments were repeated at least three times with similar results. 

A Col-0
$\operatorname{csa1-2}$
bir3-2
bak1-4 bak1-4bir3-2
bak1-4bir3-2 bak1-4bir3-2
csa1-2 \#1
csa1-2 \#2
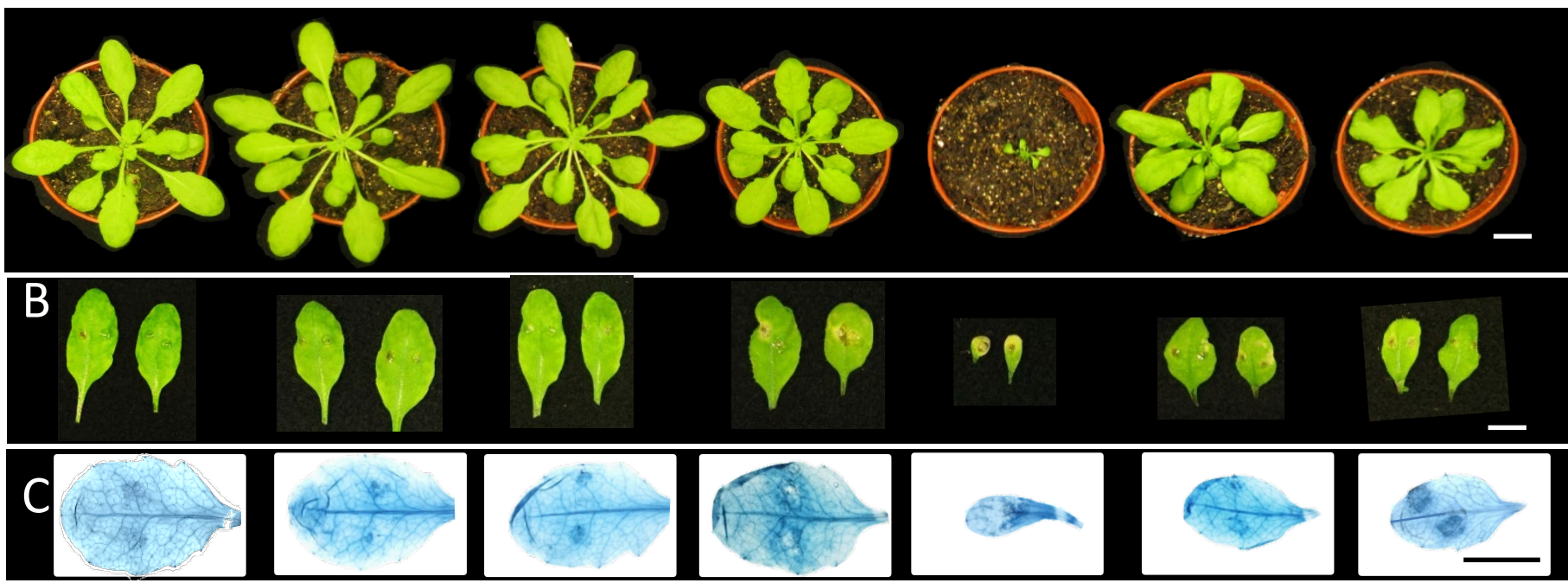

D
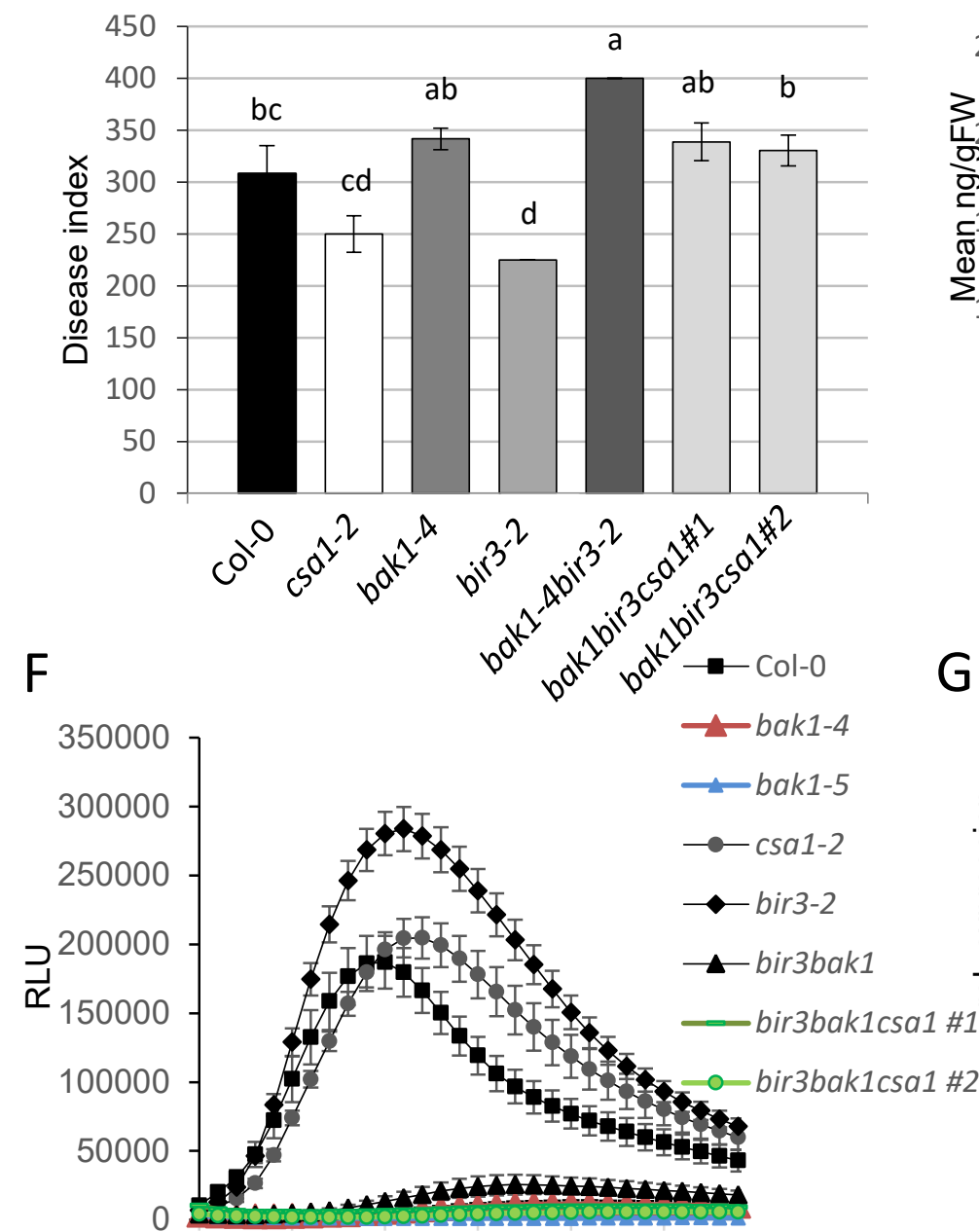

$\begin{array}{llllll}0 & 5 & 10 & 15 & 20 & 25\end{array}$

Time [min]

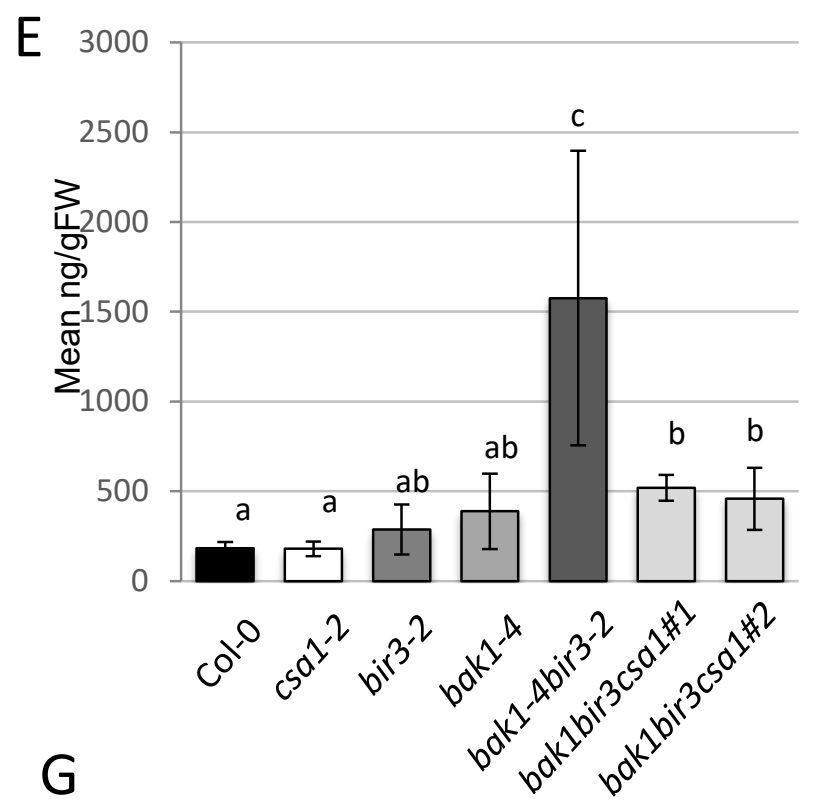

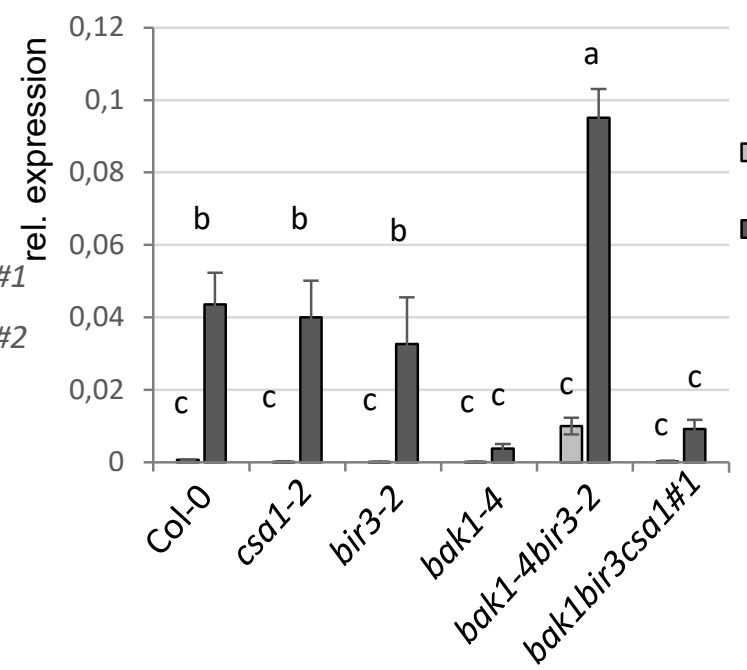

$\square$ mock

口flg22

Figure 6 
Figure 6: CSA1 is necessary for bak1 bir3-mediated cell death

A) Representative pictures of the morphological phenotypes of 6-week-old plants of the indicated genotypes are shown. (B) Alternaria brassicicola infected leaves of the genotypes shown in (A) 13 days after inoculation. (C) Infected leaves of the genotypes shown in (A, B) stained with trypan blue for cell death. The scale bar in (A), (B) and (C) represents $10 \mathrm{~mm}$. (D) Disease indices of Alternaria brassicicola infected leaves of the indicated genotypes 13 days after infection shown as mean $\pm S E(n=12)$. (E) Total salicylic acid levels measured in untreated leaf material of plants of the indicated genotypes relative to the fresh weight. (F) ROS production was measured as relative light units (RLU) in a luminol based assay. Leaf pieces of plants of the indicated genotypes were elicited with $100 \mathrm{nM}$ flg22 and ROS production was measured over a period of $30 \mathrm{~min}$. Values are mean \pm SE $(n=9)$. (G) FRK1 marker gene expression in leaves of plants of the indicated genotypes was measured by qRT-PCR analysis 3 hours after $100 \mathrm{nM}$ flg22 or mock treatment. FRK1 expression was normalized to EF1a. Results are mean \pm SE $(n=9)$. Different letters indicate significant differences according to one-way ANOVA and Tukey's HSD test $(p<0.05)$. The experiments were repeated at least three times with similar results. 
A

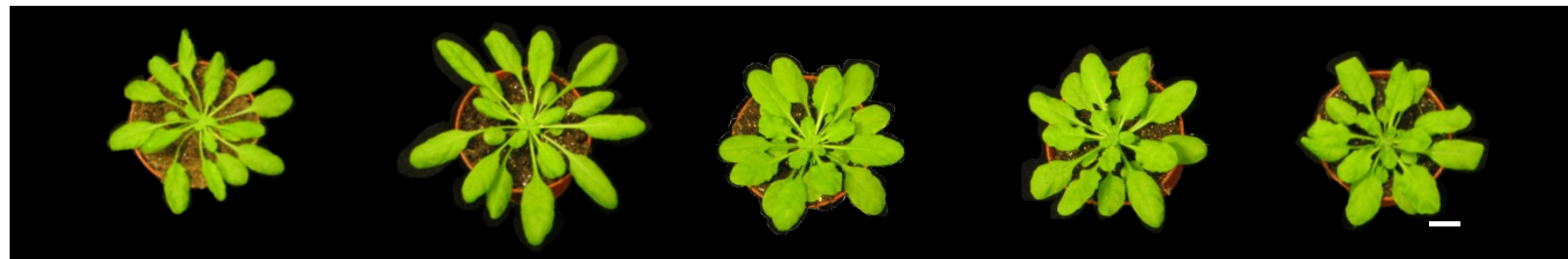

B

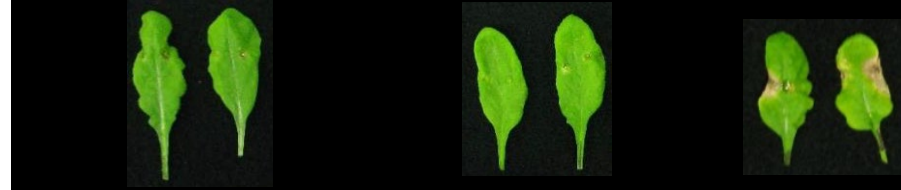

C
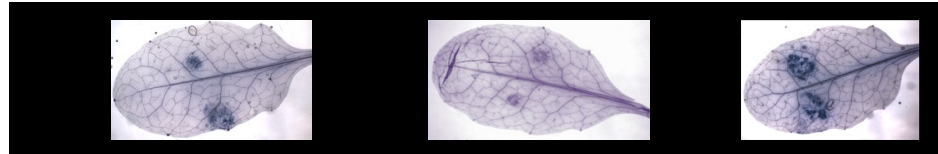

D
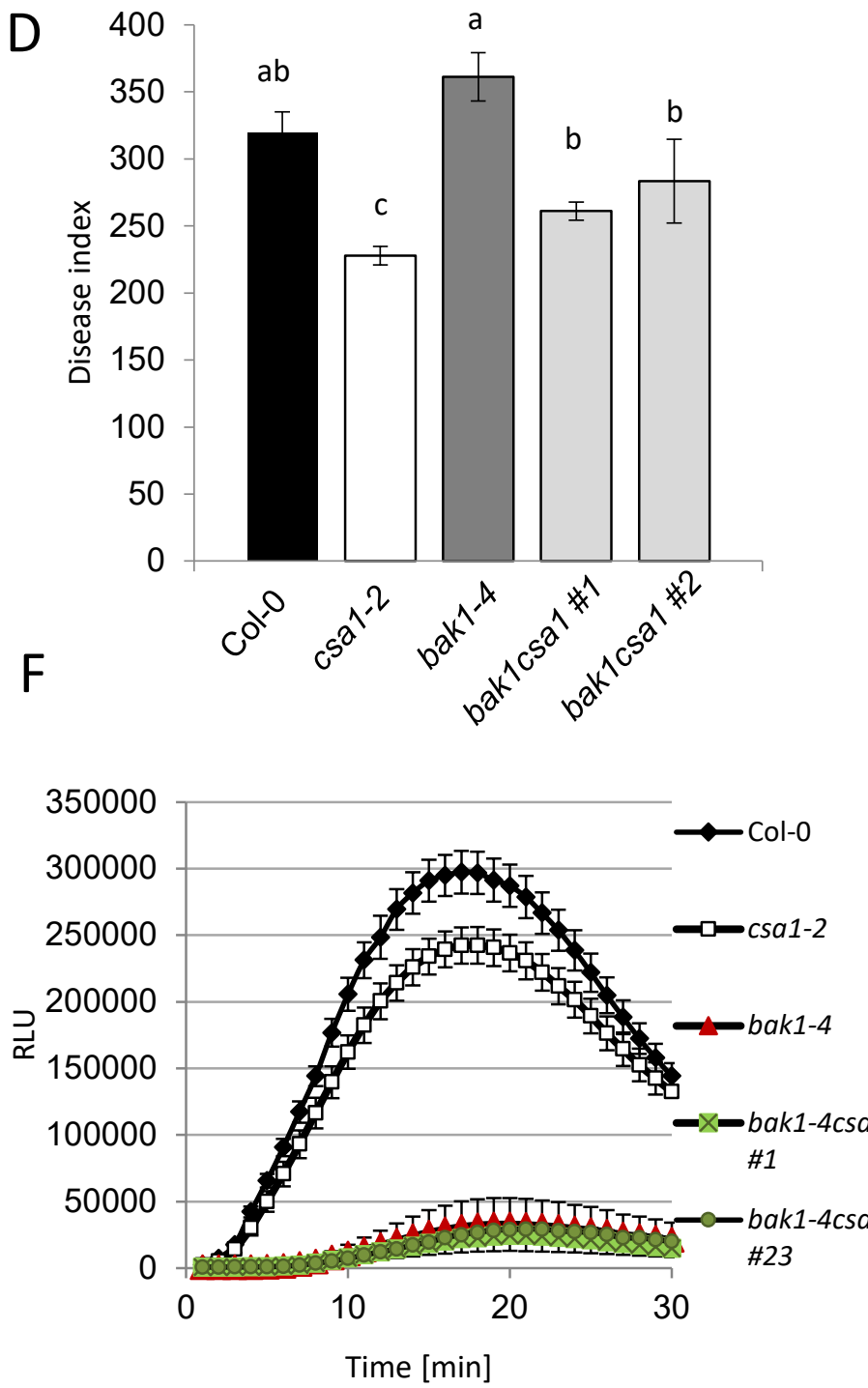

0,000

E

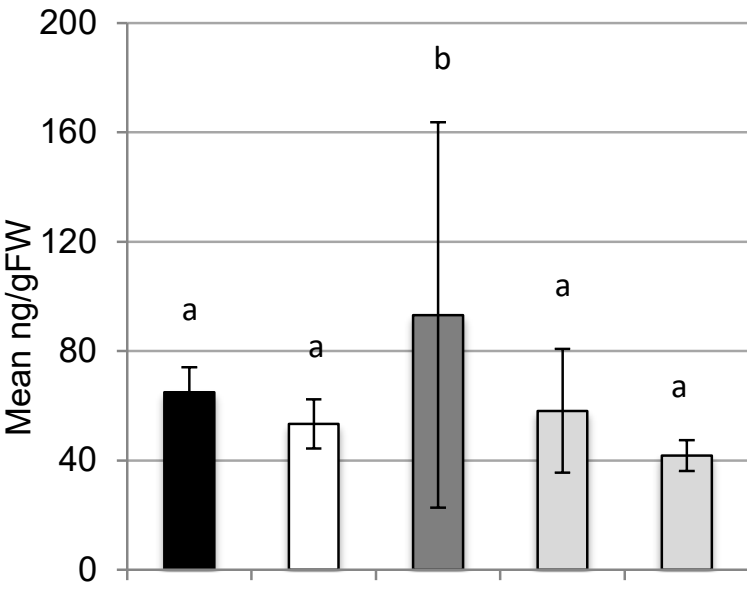

Col-0 csa1-2 bak1-4 bak1-4 bak1-4 csa1-2 csa1-2 \#1 \#2

mock

aflg22

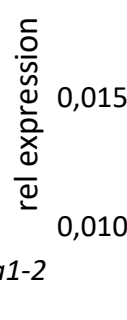

$2^{0,005}$

a

Col-0 csa1-2 bak1-4 bak1-4 csa1-2 
Figure 7: CSA1 is necessary for bak1-mediated cell death but not for flg22 responses.

A) Representative pictures of the morphological phenotype of 6-week-old plants of the indicated genotypes are shown. (B) Alternaria brassicicola infected leaves of the genotypes shown in (A) 13 days after inoculation. (C) Infected leaves of the genotypes shown in (A) stained with trypan blue for cell death. The scale bar in (A), (B) and (C) represents $10 \mathrm{~mm}$. (D) Disease indices of Alternaria brassicicola infected leaves of the indicated genotypes 13 days after infection shown as mean $\pm \mathrm{SE}$ $(n=12)$. (E) Total salicylic acid levels measured in untreated leaf material of plants of the indicated genotypes relative to the fresh weight. (F) ROS production was measured as relative light units $(R L U)$ in a luminol based assay. Leaf pieces of plants of the indicated genotypes were elicited with $100 \mathrm{nM}$ flg22 and ROS production was measured over a period of $30 \mathrm{~min}$. Values are mean $\pm \mathrm{SE}$ $(\mathrm{n}=9)$. (G) FRK1 marker gene expression in leaves of plants of the indicated genotypes was measured by qRT-PCR analysis 3 hours after $100 \mathrm{nM}$ flg22 or mock treatment. FRK1 expression was normalized to EF1 $\alpha$. Results are mean $\pm S E(n=9)$. Different letters indicate significant differences according to one-way ANOVA and Tukey's HSD test $(p<0.05)$. The experiments were repeated at least three times with similar results. 